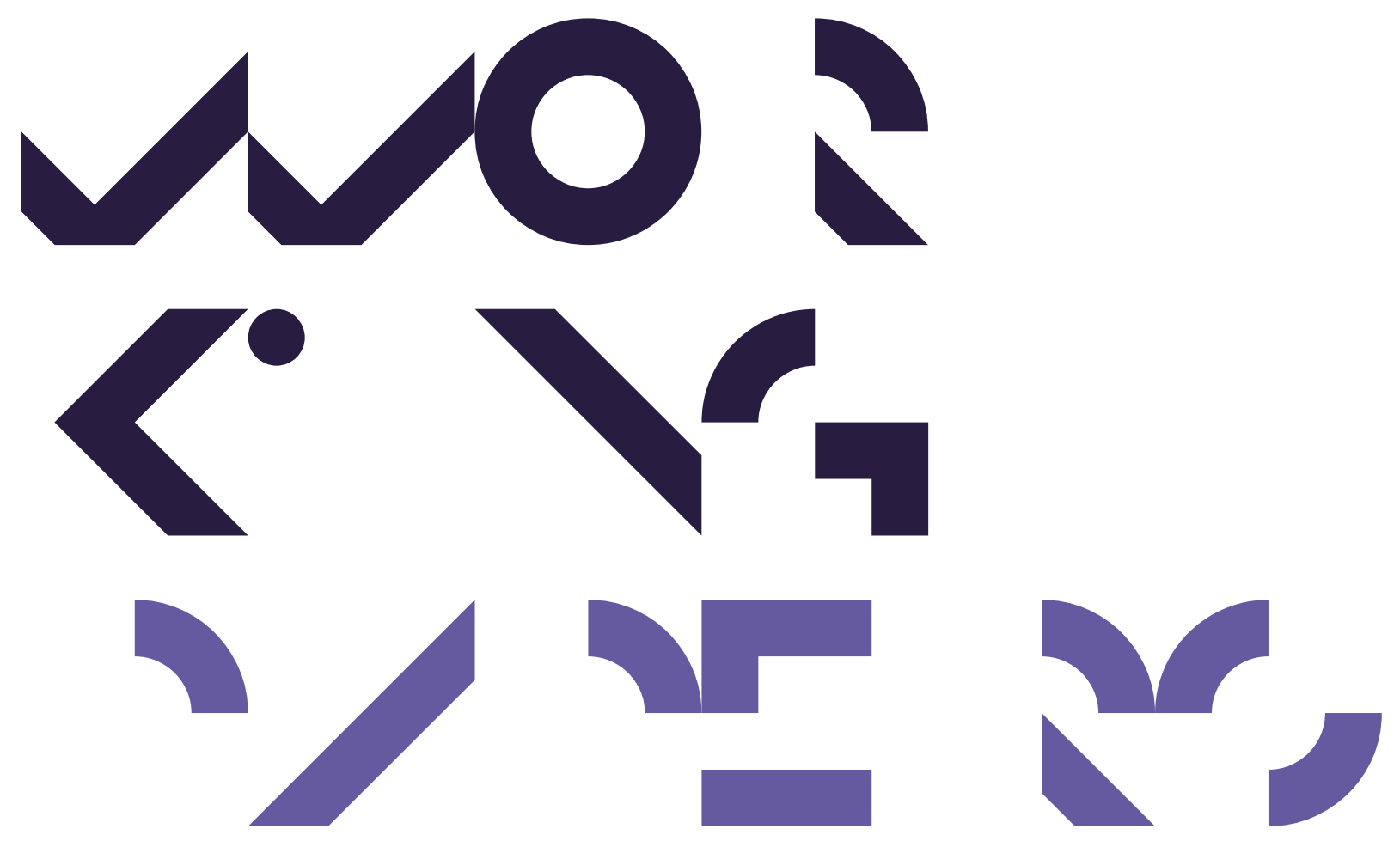

Economics Working Papers

2013-21

The Intergenerational Inequality of Health in China

Tor Eriksson, Jay Pan and Xuezheng Qin 


\title{
The Intergenerational Inequality of Health in China
}

\author{
Tor Eriksson \\ Department of Economics and Business, Business and Social Sciences, Aarhus University \\ Sino-Danish Center for Education and Research \\ Jay Pan \\ West China School of Public Health, Sichuan University \\ Western China Research Center for Rural Health Development, Sichuan University \\ Xuezheng Qin \\ School of Economics, Peking University
}

\begin{abstract}
This paper estimates the intergenerational health transmission in China using the 1991-2009 China Health and Nutrition Survey (CHNS) data. Three decades of persistent economic growth in China has been accompanied by high income inequality, which may in turn be caused by the inequality of opportunity in education and health. In this paper, we find that there is a strong correlation of health status between parent and their offspring in both the urban and rural sectors, suggesting the existence of intergenerational health inequality in China. The correlation is persistent with different health measures and various model specifications, and is robust when unobserved household heterogeneity is removed. We also find that the parents' (especially the mothers') socio-economic characteristics and environmental / health care choices are strongly correlated with their own and their children's health, supporting the "nature-nurture interaction" hypothesis. The Blinder-Oaxaca decomposition further indicates that $15 \%$ to $27 \%$ of the rural-urban inequality of child health is attributable to the endowed inequality from their parents' health. An important policy implication of our study is that the increasing inequality of income and opportunity in China can be ameliorated through the improvement of the current generation's health status and living standards.
\end{abstract}

Keywords: Intergenerational transmission; Health; Inequality; China

JEL classification: I14; I12

\section{Acknowledgements:}

We are grateful to the National Natural Science Foundation of China (71103009 to X. Qin, 71303165 to J. Pan), Ministry of Education of China (12JZD036) and the Sino-Danish Center for Education and Research for their financial support. We thank UNC Carolina Population Center for providing the data. Participants at the Beijing Conference on Inequality, Growth and the Middle-Income Trap in China, the 3rd Joint Aarhus-Xiamen Workshop in Economics, the CES Conference (Chengdu), and the $25^{\text {th }}$ EALE Conference (Turin) offered helpful comments on earlier versions. 


\section{Introduction and Background}

Three decades of persistent high economic growth in China has been accompanied by an increasing inequality in income. A growing literature has documented and analyzed the sources of the internationally large income differences between individuals, households, regions and the urban / rural areas (Shi and Sicular (2012)). Considerably less attention has been paid to income mobility over individuals' life cycles and the intergenerational persistence of income differences. As for the latter, four recent studies (Zhang and Eriksson (2010), Eriksson and Zhang (2012), Gong, Leigh and Meng (2012) and Quheng, Gustafsson and Shi (2013)) have documented (i) internationally high and persistent inequality in opportunity, (ii) that income inequality is to a high extent explained by inequality of opportunity, and (iii) there are high and persistent income correlations between parents and their offspring in the rural as well as the urban areas in China. While this research implies that the high levels of income inequality are very likely to persist in the future, it does not inform us how this development can be turned around as we know relatively little about which mechanisms are important in generating the low level of intergenerational mobility. Two prime candidates are inequality of opportunities in education and health. The current paper is concerned with the latter.

The paucity of research based knowledge about the underlying mechanisms of intergenerational income inequality does not only pertain to China but also more generally to the international literature on intergenerational mobility. ${ }^{1}$ In developing countries, health plays an important role as a determinant of income (Deaton, 2003), and we know from a burgeoning research literature on the determinants of health that especially early childhood conditions are key (Case, Fertig and Paxson (2005); Currie (2009), (2011)). Consequently, it is interesting to examine to what extent ill health is transferred across generations and to search for factors that contribute to breaking the correlation. Related to this are a number of issues like: to what extent is the transfer of poor health from one generation to the next a question of lack of resources (low income), residence in areas with differing access to health care, lifestyle and food, basic education and environmental hazards? Can the transfer of health from parents to their offspring explain the strong similarity in income between siblings and between children and their parents?

${ }^{1}$ For one of the few exceptions, see Lefgren, Lindquist and Sims (2012). 
In China, the preferential treatment of urban areas, which among other things implies different health care systems for urban and rural residents, led in the period of 1985-1993 to an increasing gap in health status between urban and rural sectors (Liu, Hsiao and Eggleston (1999)). Liu, Fang and Zhao (2012) further show that for children, the urban-rural health and nutritional disparities have remained large (although decreasing) during the period of 1989-2006. The health inequality, which is also evidenced by several other studies such as WHO (2001), is in turn correlated with the urban-rural disparity in income, education, environment, and access to health care. The residential registration regime (the hukou system), which restricts internal migration from countryside to urban cities, also tends to exacerbate the health disparity (Liu, Hsiao and Eggleston, 1999; Gao et.al, 2001). The persistent urban-rural inequality in health raises concerns regarding the already segregated and unbalanced development paths between the two sectors. Thus, it is important to examine the role of intergenerational health transmission in accounting for the health inequality, justifying separate analyses on urban and rural populations.

The aim of this paper is threefold. First, we study the intergenerational persistency of health using data from a long panel covering nine Chinese provinces, the focus of which is to examine how children's health is related to the health of their parents, catering for a host of other explanatory variables, notably parental socio-economic status and characteristics of the environment in which the children grow up. We exploit the longitudinal nature of the dataset, and use panel data methods to correct for the unobserved heterogeneity in documenting the intergenerational health transfer. Second, we carry out a Blinder-Oaxaca decomposition of the urban-rural child health differential in order to examine the extent to which this is attributable to observed differences in parents' health and other characteristics. Third, we study whether there are traces of nature-nurture interactions in the determinants of child health in China.

To the best of our knowledge, this is the first China-based study of the intergenerational transmission of health, and also the first study to account for the role of the intergenerational factors in examining the child health gap between urban and rural areas in China. Needless to say, the results regarding intergenerational health inequality and the urban-rural child disparity have potentially important policy implications for the most populous country in the world.

The remainder of the paper is organized as follows. Section 2 gives a short overview of previous research on intergenerational mobility. In Section 3 we describe the benchmark 
econometric model and its extensions. Moreover, the Blinder-Oaxaca decomposition analysis and the analysis of the nature-nurture interaction hypothesis are presented. A description of data and the key variables are given in Section 4. Section 5 presents the results. A summary of findings and their implications for policy and future research concludes the paper.

\section{Previous Research - A Brief Review}

Since the early 1990's there has been a renewed interest in intergenerational mobility issues among economists. This was chiefly due to the very influential papers by Solon (1992) and Zimmermann (1992) that reconsidered the methodology for measuring the phenomenon. In particular, they demonstrated that the earlier studies had significantly overestimated the degree of social mobility and economic opportunities. ${ }^{2}$ As pointed out in Solon's (1999) survey, there are basically two ways one can address the intergenerational mobility issue: either by examining the parent-offspring income disparity or by studying sibling similarity in incomes. Most studies have adopted the former approach although it has the disadvantage of being based on one single characteristic of the family - typically of the father - and is, furthermore, associated with considerable demands on the data to be used. ${ }^{3}$

Parent-offspring income correlations vary across countries, but for many countries they are in the neighborhood of 0.3; see Björklund and Jäntti (2009) for a survey. The estimates are quite sensitive to differences in the data used and in some countries also to the period studied. The estimates from the siblings approach are as a rule substantially higher, which is to be expected as sibling income similarity is the fraction of the total variation in incomes that can be attributed to variation in the family component - that is, not only factors directly related to parents' income but also values and aspirations - shared by the siblings in the family. As emphasized by Björklund and Salvanes (2011), the sibling correlation is a lower bound of family and neighborhood effects as parents may have treated their offspring differently.

A lot of attention has been paid to the difference between intergenerational mobility in U.S.

\footnotetext{
2 The new literature that uses the improved methods and data is summarized and discussed in Solon (1999). The more recent research efforts are reviewed in Björklund and Jäntti (2009), (2012) and Black and Devereux (2011).

${ }^{3}$ Not only are observations on earnings from generations at roughly the same age needed but in order to reduce the noise in the lifetime income measure (which likely leads to downward biased estimates) earnings should also be measured after the beginning of the individuals' labor market careers and preferably over a number of years.
} 
as compared to other advanced industrialized countries; see e.g., Björklund et al. (2002), Grawe (2004) and Corak (2013). Studies of intergenerational mobility in developing economies are rare. $^{4}$ The study by Grawe (2004) reports father-son income elasticities for five developing countries (Ecuador, Malaysia, Nepal, Pakistan and Peru) and finds that these are internationally high and in particular for the Latin American countries much higher than in the United States. Dunn's (2007) estimates for Brazil also exceeds those obtained for U.S. and European countries.

For China we are aware of three studies of intergenerational income mobility. Gong et al. (2012) estimate parent-offspring income elasticities from data from urban areas in twelve provinces. They use a survey from 2004 to retrieve information about the offspring's incomes (plus characteristics of their parents) while parents' incomes are predicted from repeated cross-section data from years 1986-2004. The results show notably high intergenerational income persistence. Another study by Eriksson and Zhang (2012) makes use of the same data source $^{5}$ as the current paper to estimate sibling correlations in earnings for rural areas in nine provinces. The low intergenerational mobility is found to be present also in the rural parts of China. Finally, a recent paper by Quheng et al. (2013) uses data from CHIP 1995 and 2002 (from 69 and 70 cities in 11 provinces, respectively) to estimate parent-offspring income elasticities, and find high intergenerational income persistency.

The growing literature documenting intergenerational income mobility has not been accompanied by a corresponding growth in research based knowledge about the mechanisms giving rise to resemblance in incomes between parents and children and between siblings. What research there is, predominantly deals with cognitive skills. This is logical as the standard economic model for intergenerational transmission (Becker and Tomes (1979)) is concerned with parents' investments in their children's human capital.

Although human capital typically is interpreted as the stock of cognitive skills, it can be much broader and include non-cognitive skills, health and personality characteristics (Bowles, Gintis and Osborne (2001)). Blanden, Gregg and Macmillan (2007) find a non-trivial role for non-cognitive skills in explaining the intergenerational income elasticity, and Dohmen, et al.

\footnotetext{
${ }^{4}$ There is more research on educational persistence across generations for developing countries; see e.g., Hertz, Jayasundera, Piraino, Selcuk, Smith and Verashchagina (2008).

5 A related study, Zhang and Eriksson (2010), focuses on the role of inequality of opportunity and inequality of income.
} 
(2012) document a strong intergenerational similarity in personality characteristics like risk and trust attitudes. A recent book edited by Ermisch, Jäntti and Smeeding (2012) contains a number of studies of the intergenerational transmission of both cognitive and non-cognitive skills in highly developed countries.

The potentially important role for health as a part of the transmission process of socio-economic status across generations has been pointed out by e.g., Bowles, Gintis and Groves (2005) and Case et al. (2005), but the dearth of adequate data has greatly hampered the research of intergenerational transmission of health. There are a number of studies of correlations of parents' and offspring's birth weight (see Currie and Moretti (2007) and references therein) ${ }^{6}$ but only a few have focused on health outcomes as adults. One is an unpublished paper by Eriksson, Bratsberg and Raaum (2007) that makes use of the Danish Youth Cohort Study where the respondents are asked to answer a battery of questions concerning their own health (when they are in their early fifties) and then later the same questions are asked about their parents' health. The study finds fairly strong correlations in health problems across generations and moreover, that accounting for health gives a significant reduction in the intergenerational income mobility measures used. In another unpublished paper, Akbulut and Kugler (2007) utilize NLSY data in estimating intergenerational elasticities for weight, height, BMI, depression and asthma for natives and immigrants, separately. They find that children inherit a sizable fraction of their health status from their parents.

There is considerably more research on the impact of early-life health on adult outcomes; a recent review is provided in Almond and Currie (2010). Summing up, this literature shows that early life health does have decisive impacts on individuals' future outcomes like education and earnings and that inequality begins already before children reach school age, and indeed, even prior to birth. ${ }^{7}$ The new science of epigenetics has shown that health differences at birth are not primarily due to genetic factors but are more likely to reflect interactions between nature and nurture; see Currie (2011) for a summary (accessible to economists) of this research.

The bulk of the literature on the impacts of early life health is based on analyses of data

\footnotetext{
${ }^{6}$ See also Bhalotra and Rawlings (2013) for a study of the relationship between maternal health and infant mortality risk and child height based on a large sample collected from 38 developing countries.

${ }^{7} \mathrm{~A}$ large part of the empirical studies have focused on health before birth. This is in part inspired by the so called Barker hypothesis, emphasizing conditions in utero, but also because the pre-birth period and the health shocks during it are well defined.
} 
from rich countries. But there is also a small but growing stock of studies of early health shocks on data sets from developing countries. For example, Smith et al. (2012) find strong effects of childhood health (measured by height and self-rated health status) on the health and economic outcomes (such as consumption expenditures) of adults over 45 in two Chinese provinces. In a recent review of such studies, Currie and Vogl (2013) emphasize that the long-term effects of early childhood health shocks are likely to be larger in poorer countries. Here, health shocks are not only more likely to occur but also to interact. As the starting levels of health are lower, the probability that a given shock has detrimental / larger effects is higher than in developed countries where mitigation is available to larger extent and more effective. Studies of developing countries have typically focused on height as the health variable ${ }^{8}$ and the health shocks considered are malnutrition (of which famines are an extreme case), diseases, pollution and war.

The majority of China-based studies on early life health consequences examine the long-term effects of the great famine triggered by the Great Leap Forward; see Meng and Qian (2009),Chen and Zhou (2007), Almond, Edlund, Li and Zhang (2010), Gorgens, Xin and Vaithianathan (2012). Dramatic shocks like famines, epidemics and wars are, however, associated with mortality selection which, if not controlled for, yields a downward bias in the estimated effects of the shock. Pollution of air, water and soil is a health shock that is typically stronger in developing countries, affects poor people proportionately more (as they lack the means to move out of polluted areas) and often affects children more than adults (as children are still developing and because of their smaller size receive a higher doses per body mass). All in all, this suggests that environmental pollution may have very large longer term adverse effects on child development in less developed countries. Most of the research on the consequences of pollution is, however, from developed countries, in particular the United States. ${ }^{9}$

\section{Econometric Model and Estimation}

\subsection{The Benchmark Model of Intergenerational Health Transmission}

To examine the intergenerational inequality of health in China, we start by formulating a

\footnotetext{
${ }^{8}$ This is a broader measure than weight which mainly captures differences in nutrition, whereas height also reflects other health conditions in early critical periods of life.

${ }^{9}$ Currie (2011) reviews and discusses some of these studies, which all are of relatively recent date.
} 
benchmark model which characterizes the transmission of health capital from parents to their offspring, conditional on other influencing factors:

$$
\text { CHealth }_{i t}=\alpha_{0}+\alpha_{m} \text { MHealth }_{i t}+\alpha_{f} \text { FHealth }_{i t}+\theta X_{i t}+\gamma W_{i t}+\delta E_{i t}+\lambda H_{i t}+u_{i t}
$$

The outcome variable in equation (1) is $\mathrm{CHealth}_{i t}$, which denotes the health status of child $i$ in period $t$, measured by two different indicators: the height-for-age and weight-for-age $\mathrm{z}$ scores calculated based on the child's height and weight data using the WHO standard. The two key explanatory variables in equation (1) are MHealth ${ }_{i t}$ and FHealth $_{i t}$, which are the health status of the mother and father of Child $i$ in period $t$, respectively. These are measured correspondingly by their height (in centimeters) and weight (in kilograms). The parameters $\alpha_{m}$ and $\alpha_{\mathrm{f}}$ thus indicate the correlation of health between the two generations, and are the key coefficients in the model. Our main focus will be on parental height as this is a widely adopted measure of adult long-term health, especially in developing countries. ${ }^{10}$

The additional explanatory variables in equation (1) capture other major determinants of health, such as the demographic, environmental, socio-economic, and health care related factors. The demographic factors are represented by a vector $X_{i t}$, which is a set of individual level variables such as the child's age, gender and the ages of parents. To control for the time trend and the regional fixed effects on children's health, $X_{i t}$ also include a set of dummy variables identifying the survey years (year93, year97, year00, year04, year06, year09) and residential regions (East, Central; omitted category is West). Another vector, $\mathrm{W}_{i t}$, contains the socio-economic characteristics of the child's family and includes the information on the household's income, the parents' educational attainment (primary school or below, middle school, high school, college or above) and their type of employment (farmer, government, state owned enterprises, collective owned enterprises, private or foreign enterprises). Thus, $\mathrm{W}_{i t}$ captures the impact of the family's accumulation of financial capital (wealth), human capital (education) and social capital (employment rank) on the child's health.

Vector $\mathrm{E}_{i t}$ is included in equation (1) to control for the environmental impact, which includes

\footnotetext{
${ }^{10}$ Adult height is frequently used as a measure of a person's long-term health and is considered as determined by childhood health and the adolescent growth spurt. The latter are affected not only by nutritional intake but also by more general health conditions and especially some infection diseases.
} 
the child's accessibility to the in-house flush toilet (as an overall hygiene indicator) and tap water (indicating improved drinking water), as well as the adult smoking prevalence rate in the Child's residential community (as a measure of in-door air pollution). Vector $\mathrm{H}_{i t}$ represents the child's access to medical care, which is measured by the distance from her residence to the closest health care facility in the community. $\mathrm{u}_{i t}$ is the random error that varies with individual and year. Equation (1) will be estimated using OLS separately for the urban and rural samples.

\section{2 Accounting for the Unobserved Heterogeneity in Health}

In the above benchmark model, it is possible that the key explanatory variables MHealth and FHealth are endogenous, leading to potential bias in the estimation of intergenerational health transfer elasticity. Theoretically, the endogeneity may arise due to three reasons: (1) omitted variables affecting the health of both the child and the parents; (2) "reverse causality" between child health and parental health; (3) measurement error in parents' reported health variables. In our model, it is not likely that (2) and (3) will be the case, as the child health cannot "reversely" affect parental health, and the health indicators employed in our model (height and weight) do not usually suffer from substantial recalling errors. Thus, the possible endogeneity will most likely arise from the unobserved factors that affect both the parents' and the child's health status ${ }^{11}$.

For example, genes are natural endowments and are transmitted from generation to generation, resulting in parents and their offspring sharing many physical traits (e.g. height, weight, inheritable diseases). Such heritable genetic characteristics are often important predictors for the child's future health outcomes, but they are unobserved by researchers and thus cannot be included in the regression. Another example is the health related habits and lifestyles shared by family members (e.g., poor diet, sedentary lifestyle, toxic exposure), which simultaneously influence both the parents' and the child's health. Such habits are largely determined by family traditions and cultural context which are unobservable from the survey data.

The abovementioned variables that influence the health of two generations are usually family specific and time-invariant characteristics, reflecting the unobserved household heterogeneity. Failing to account for such heterogeneity will mistakenly assign its explanatory power on child

\footnotetext{
${ }^{11}$ It can be argued that in some cases children's health can reversely affect parents' health; e.g. taking care of an unhealthy child can be exhausting and negatively affect parental health. However, this will not affect the parents' height, as height is a long-term health measure and does not capture shorter bouts of illness.
} 
health to other independent variables, leading to upward or downward bias in the estimates of intergenerational impacts. Due to the limited data availability, none of the existing studies have addressed this issue in estimating the intergenerational transmission of health. This paper thus improves upon earlier studies by explicitly accounting for such unobserved heterogeneity using the panel data methods. The longitudinal nature of the CHNS data allows us to eliminate any time-invariant household characteristics (heterogeneity) by means of the following model:

$$
\text { CHealth }_{i j t}=\alpha_{0}+\alpha_{m} \text { MHealth }_{i j t}+\alpha_{f} \text { FHealth }_{i j t}+\theta X_{i j t}+\gamma W_{i j t}+\delta E_{i j t}+\lambda H_{i t}+V_{j}+u_{i j t}
$$

where $i, j$ and $t$ index the person, household and year, respectively. Compared to equation (1), the added term $\mathrm{v}_{j}$ represents the unobserved household heterogeneity. We use the random effects (RE) model through the quasi-demeaned transformation (Greene, 2011) to obtain consistent estimates of $\alpha_{m}$ and $\alpha_{f}$, which are generally considered to be superior to the estimates of the basic OLS model because of the elimination of unobserved heterogeneity at the household level ${ }^{12}$.

\section{3 A Blinder-Oaxaca Decomposition of Health Inequality}

The Blinder-Oaxaca decomposition method proposed by Blinder (1973) and Oaxaca (1973) is frequently used in the economics literature to explore the sources of wage discrimination in the labor market. The method breaks the overall difference between two groups (e.g. white vs. non-white) into two components: the endowment effect which is the group difference in the observed characteristics (e.g. education and work experience), and the discrimination effect which is the group difference in the impact of these characteristics on outcomes (e.g. wage rate). In our study, the urban-rural disparity in child health can be decomposed in a similar fashion. First, the urban and rural parents are likely to have strong disparities in health endowment, socio-economic status, and other environmental and health care related characteristics, and hence a significant part of the urban-rural inequality in child health is attributable to this "endowed

\footnotetext{
12 Alternatively, the fixed effects (FE) model, which relies on less restrict distributional assumptions, could also be used to eliminate unobserved heterogeneity. However, as parents' height is basically a time-invariant explanatory variable, it would be swept away by the demeaned transformation of FE. Parental weight has somewhat more, albeit still small, within variation. We have estimated the models with FE on weight measures and obtained qualitatively similar results as for RE, but as expected parental weight loses its significance. Consequently, RE is our preferred specification.
} 
disparity" in the observed characteristics. Second, unobserved differences between the urban and rural families may also lead to heterogeneous impact of the above characteristics on children's health outcomes, resulting in the "discrimination" component in the overall health inequality (i.e. the disparity unexplained by the observables).

Formally, the twofold Blinder-Oaxaca decomposition quantifies the urban-rural differential in child health through the following equation:

$$
\overline{\text { CHealth }_{u}}-\overline{\text { CHealth }_{r}}=\left(\bar{Z}_{u}-\bar{Z}_{r}\right) B^{*}+\bar{Z}_{u}\left(B_{u}-B^{*}\right)+\bar{Z}_{r}\left(B^{*}-B_{r}\right)
$$

where the outcome variable CHealth is defined in section 3.1, and the subscript $\mathrm{u}$ and $\mathrm{r}$ denotes urban and rural sectors, respectively. $\mathrm{Z}$ is the vector of observed characteristics, which includes the sub-vectors MHealth ${ }_{i t}, \mathrm{FHealth}_{i t}, \mathrm{X}_{i t}, \mathrm{~W}_{i t}, \mathrm{E}_{i t}$, and $\mathrm{H}_{i t} \mathrm{~B}$ is the associated coefficient vector, with $\mathrm{B}^{*}$ denoting the nondiscriminatory coefficients (the benchmark impact of $\mathrm{Z}$ ). Thus, the first term on the right hand side of equation (3) captures the endowment effect (the health disparity explained by Z), and the other two terms jointly capture the discrimination effect (the part of health inequality due to unobserved factors).

This decomposition requires estimation of $\mathrm{B}^{*}$, the impact of $\mathrm{Z}$ on $\mathrm{CHealth}$ in the absence of a discrimination effect. Following the convention in prior studies (e.g. Bowblis et al., 2013), we assume that the urban group is immune to "discrimination", and is consequently used as the base category. This assumption is justified by the higher socio-economic status (including income, education, health care and employment) enjoyed by the urban residents. On the other hand, the rural hukou holders have traditionally been in disadvantage and are restricted from migrating into the cities. Replacing $\mathrm{B}^{*}$ with $\mathrm{Bu}$ (the coefficient vector associated with the urban sample), equation (3) can be re-written as:

$$
\overline{\text { CHealth }_{u}}-\overline{\text { CHealth }_{r}}=\left(\bar{Z}_{u}-\bar{Z}_{r}\right) B_{u}+\bar{Z}_{r}\left(B_{r}-B_{u}\right)
$$

Based on equation (4), we can calculate the endowment effect (the first right-hand-side term) and the discrimination effect (the second right-hand-side term) using the group means of the 
urban / rural samples and the coefficient estimates in the benchmark models. For example, the endowment effect is the summed products of group differences of each variable in vector $\mathrm{Z}$ multiplied by their estimated coefficients from equation (1), and the discrimination effect is obtained in a corresponding manner. Furthermore, the standard errors and statistical significance of the two estimated effects can be computed using the delta method specified in Morduch and Sicular (2002) and Jann (2005).

Based on the definition of vector $\mathrm{Z}$, we further identify the detailed sources of health disparity by decomposing the total endowment effect and the total discrimination effect respectively into six dimensions: parent health $\left(\right.$ MHealth $_{i t}$ and FHealth ${ }_{i t}$ ), parent socioeconomic status as represented by the variables in vector $\mathrm{W}_{i t}$, household environment $\left(\mathrm{E}_{i t}\right)$, access to health facilities $\left(\mathrm{H}_{i t}\right)$, demographic variables (child's age and sex, parent age), and the other factors (such as the year and region fixed effects). The contribution of each dimension can be calculated by the same method as the total effects. For instance, the endowed intergenerational health inequality is obtained by summing over the group difference between father's and mother's health, each multiplied by their coefficient estimates. Among the six dimensions, our key interest lies in the impact of parental health, which is now decomposed into endowed and discriminatory effects. The endowment effect reveals the contribution of the observed parental health to their children's health inequality, thus can be considered as the direct intergenerational health inequality between the urban and rural sectors. The discrimination effect reflects the different elasticities of health transmission (the heterogeneous impact of parent health between urban and rural families), which can be considered as the indirect intergenerational health inequality.

\subsection{The Nature-Nurture Interaction in Intergenerational Health Transmission}

The medical literature traditionally divides the determinants of human health into two categories: nature, which represents the genetic endowment at birth such as inborn traits and abilities; nurture, which represents the acquired traits and abilities due to environmental influences or personal behavior. However, recent studies in medical sciences and health economics have accounted for and consistently documented the interaction between the two dimensions. In particular, many differences in health outcomes that are often conceived of as being innate may in fact reflect the effects of "nurture" or individual choices (Currie, 2011). 
For example, height is a heritable genetic trait that is a strong predictor of a person's health outcomes. However, the sequencing of human genome indicates that there are too few genes in the human body to fully explain the variation in height between individuals. Instead, the epigenome (the genetic "switch" that determine which genes are expressed through inheritance) plays an important role in the determination of height outcome. The epigenome switches, which are easily triggered by environmental factors and largely determine health outcomes (such as height, weight and inheritable diseases), may interact in at least three ways with the nurture factors:

(1) A large body of research on the "fetal origin" suggests that adult health outcomes are to a high extent determined before the person is born, and access to medical care in the prenatal and nursing period is a critical determinant of an individual's health in childhood, adulthood and even in the next generation; see Almond and Currie (2011) for a review on this topic.

(2) During the prenatal period, both the pregnant mother and the in utero child may adapt to changes in the natural environment. Thus, the environmental choices made by the parents (e.g. regarding exposure to toxic substance, polluted air and water) also play a significant role in the child outcomes. Relevant studies can be found in Currie (2011), Lien and Evans (2005), Nilsson (2008), Currie and Neidell (2009), and Banzhaf and Walsh (2008).

(3) Parental socio-economic status (such as income and education) largely determines the quality of care and nutrition intake received by the child during the in utero period and childhood, and consequently the adaptation to the social environment is also an important channel of the nature-nurture interplay; see Currie and Moretti (2003), Johnson and Schoeni (2011), and Chen and $\operatorname{Li}(2009)$.

Through the above mechanisms, the nurturing factors are able to model the epigenome switches and the expression of genes, and thus make a difference in the intergenerational transmission of health. We adopt the following model to explore this potential interaction between nature and nurture:

$$
Z_{i j t}=\beta_{0}+\beta_{m} \text { MHealth }_{i j t}+\beta_{f} \text { FHealth }_{i j t}+\theta X_{i j t}+V_{j}+u_{i j t}
$$


$\mathrm{Z}_{i j t}$ denotes the nurturing factors that contribute to the health of child $\mathrm{i}$ in household $\mathrm{j}$ and period t. Based upon the previous analysis, $\mathrm{Z}_{i j t}$ includes the parents' socio-economic status $\left(\mathrm{W}_{i j t}\right)$, the parents' choice of environmental influences on their child $\left(\mathrm{E}_{i j t}\right)$, and the child's access to medical care $\left(\mathrm{H}_{i j t}\right)$. MHealth ${ }_{i j t}$ and FHealth $\mathrm{ijt}_{i j}$ denote the health of mother and father respectively, which represent the "nature" (or hereditary) determinant of child i's health, and are measured by the aforementioned indicators. $\mathrm{X}_{i j t}$ controls the individual characteristics as defined in Section 3.1. As in section 3.2, we control for unobserved household heterogeneity $\left(\mathrm{v}_{j}\right)$ by estimating equation (5) using the RE model. The estimation will be based on the urban and rural samples separately to reflect the different mechanisms of health transmission between the two sectors.

In equation (5), $\beta_{m}$ and $\beta_{f}$ are the key parameters. They represent the correlation between the parents' health status (the nature factors) and their environmental and behavioral choices (the nurture factors). Positive $\beta$ 's indicate that the healthier parents tend to exert better nurturing influences on their children's health, and the nature-nurture interaction tends to exacerbate the intergenerational transfer of health capital. For example, healthier parents may seek to live in a "cleaner" environment (measured by usage of improved drinking water, flush toilet and less exposure to air pollution), or they may on average enjoy better access to medical care by choosing to live closer to a medical facility. It can also be the case that healthier parents tend to be wealthier, better educated and enjoy higher social status (see Cutler, Lleyras-Muney and Vogl (2011) for a review on the health-SES gradient). Since such nurturing choices would all benefit the health of child [revealed by $\gamma, \delta, \lambda$ in equation (2)], the signs and statistical significance of $\beta$ 's will shed light on the mechanisms of the intergenerational health transmission, and will provide verification of the hypothesized nature-nurture interaction in China.

\section{Data and Sample}

\subsection{Data Source}

The data used in this paper are from the 1991-2009 China Health and Nutrition Survey (CHNS), which is an ongoing international collaborative project since 1989 between the Carolina Population Center at University of North Carolina at Chapel Hill and the Chinese 
Center for Disease Control and Prevention. ${ }^{13}$ The survey is longitudinal and has so far included eight waves (1989, 1991, 1993, 1997, 2000, 2004, 2006 and 2009). In each round of surveys, CHNS uses a multistage random cluster process to draw a sample of about 4,400 households with a total of 15,000 to 19,000 individuals in nine provinces (Guangxi, Guizhou, Heilongjiang, Henan, Hubei, Hunan, Jiangsu, Liaoning, and Shandong) that vary substantially in geographic and economic characteristics. In each province, four counties are randomly selected based on a weighted sampling scheme; within each county, "communities" are randomly selected as primary sampling units (PSU) which represent urban / suburban neighborhoods and rural towns / villages. The household / individual survey collects detailed information on the respondent's socio-demographic characteristics, health status and nutrition intake, the utilization and expenses of medical care, etc. The community survey provides information on the local hygiene condition, public service infrastructure, health care resources, insurance coverage profile, etc. Moreover, the panel feature of the CHNS data allows us to track the changes in individual characteristics over the years, thus enabling the better control for the unobserved individual heterogeneity.

For the present study, we first collect the pooled samples from the 1991-2009 waves of CHNS data and use the parent-child identifiers to select a sample consisting of parent-offspring pairs. We restrict our sample to children less than 18 years of age. For families with multiple children, their family bond (and thus the family fixed effects) is identified by household IDs. The demographic, socio-economic and health related information of the child and parents is extracted from the CHNS child and adult questionnaires, respectively. The household questionnaire is used to obtain the information about family income as well as the household's access to improved drinking water and toilet facilities. Moreover, the community level restrict-use files are employed to extract data on the other environmental characteristics, such as the access to the nearby hospitals and the adult smoking rate within the neighborhood. The resulting study sample consists of 16,057 non-adult observations with matching parental information, among which 4,398 live in urban areas and 11,659 in the rural regions.

The central outcome variable in our model is child health, which is measured by the height-for-age and weight-for-age $\mathrm{z}$ scores based on the anthropometrical records in $\mathrm{CHNS}^{14}$. A

\footnotetext{
${ }^{13}$ See http://www.cpc.unc.edu/china for a detailed description of the project and data constructed within it.

${ }^{14} \mathrm{CHNS}$ also contains subjective health measures (self-rated health status) for parents and children above 12.
} 
large body of medical research has shown that such anthropometric indices are good indicators for children's short-term and long-term health outcomes in developing countries. In particular, the height-for-age z score is consistently recognized as the best indicator (Thomas et al., 1991; Strauss and Thomas, 1998), and has been widely used as a health proxy measure for studies on Chinese children (Chen and Li, 2009; Mangyo, 2008; Chen et al., 2010). Adult height is also frequently used as a measure of a person's long-term health especially in developing countries. We thus focus on the height measures (child height-for-age $\mathrm{z}$ score and parent height) in the following analyses, and use the weight measures as a robustness check. The $\mathrm{z}$ scores are calculated as the deviation of a child's observed height / weight from the median value of the reference population, divided by the standard deviation of the group in the following way:

$$
z \text { score }=\frac{(\text { observed value })-(\text { median reference value })}{\text { standard deviation of reference population }}
$$

where the observed values are the child's height /weight records, the reference group is defined by the child's gender and age (in months), and the median and standard deviation for each group is calculated on an international scope and published by the WHO Multicentre Growth Reference

Study (MGRS) ${ }^{15}$. The z score reflects the relative growth level of a child compared to children of the same cohort, and has an important advantage over the absolute height / weight measures and the percentile measures (World Health Organization, 1995). Prior research consistently finds that $\mathrm{z}$ scores reveal the long-term health and nutritional conditions, and low levels of $\mathrm{z}$ scores are often associated with early exposure to adverse medical events or inappropriate feeding.

\subsection{Sample Description}

Table 1 reports the sample summary statistics of key variables; columns (1) - (3) represent the full sample and the urban / rural samples (defined by CHNS sites), respectively.

\footnotetext{
However, this indicator may not be reliable, as many children of this age cannot evaluate their overall health in an objective and precise manner, and their reference groups can be very different thus making their evaluation incomparable. For the above reasons, we did not use the subjective health indicators in our study.

${ }^{15}$ MGRS website http://www.who.int/childgrowth/mgrs/en/; formulae for height-for-age z scores are provided for children under 18, and formulae for weight-for-age z scores are provided for children age 10 or under. This is reflected in the smaller sample size for the regressions for the weight-for-age $\mathrm{z}$ scores.
} 
The children in our sample are 9.9 years old on average, and girls account for $46.7 \%$. The urban group is slightly older (10.1 years of age) with a higher female representation (48.4\%). The average, negative height-for-age $(-0.976)$ and weight-for-age $(-0.568)$ z scores indicate that the Chinese children's health is below the world growth standard. The average age of the sample children's father and mother is 38 and 36.4, respectively, and their height and weight measures are $166.3 \mathrm{~cm} / 61.9 \mathrm{~kg}$ for fathers and $155.7 \mathrm{~cm} / 54.3 \mathrm{~kg}$ for mothers. The statistics on the geographic distribution indicate that $27 \%$ of our sample is collected from provinces in eastern China (Jiangsu, Liaoning, Heilongjiang, and Shandong) and $43.2 \%$ and $28.5 \%$ are from central (Henan, Hubei and Hunan) and western China (Guangxi and Guizhou), respectively.

In terms of parent socio-economic variables, the average annual household income per capita is 2,766.5 Yuan, and the average approximate years of schooling is 8.5 for fathers and 6.9 for mothers, reflecting the gender difference in educational attainment. The majority of the sample parents (about $71.9 \%$ of fathers and $66 \%$ of mothers) work in a collective enterprise or the government sector (including state-owned enterprises). Since our data spans from 1991 to 2009, the full sample average does not reflect the dramatic ownership structure changes that have taken place in China's industrial sectors during the past decade, the transformation from the dominance of state-owned and collective enterprises to the dominance of private firms.

The environmental variables indicate that more than half of the families $(61.6 \%)$ in our sample have access to tap water and only $24.8 \%$ have in-house flush toilets. The average rate of adult smoking (defined as the number of smoking adults as a percentage of community population above 18) is $33.5 \%$ in the sample communities, reflecting the high smoking prevalence among Chinese population. The average distance from household residence to the nearest health facility is $0.39 \mathrm{~km}$, which reflects the easily accessible primary care in China.

Due to the urban-rural gap in the economic and infrastructural development, substantial and statistically significant (indicated by asterisks in Table 1) differences exist in practically all dimensions between the two sub-samples. Among the outcome measures, the rural children are found to be both shorter (-1.07 vs. -0.73$)$ and thinner (-0.64 vs. -0.37$)$ than their urban counterparts, indicating poorer performance in physical development, overall health status, and 
nutrition intake. A comparison between the two groups' parents reveals the same pattern, with the rural parents having significantly lower values for both anthropometric indicators.

For the socio-economic variables, the urban-rural differential is even more noticeable. The urban households have an average annual per capita income of 3,886.7 Yuan, almost 1.6 times higher than the rural households $(2,431.8$ Yuan $)$. The percentage of parents who received high school education or above is 34.9 (father) and 28.9 (mother) in the cities and only 20.6 (father) and 12.4 (mother) in villages and towns. The sharp distinction in education attainment reflects the large gap in human capital accumulation and the "nurturing environment" of children between the two sectors. This gap is also present in individuals' social capital, which is proxied by the parents' employment ranks. In China, a job in the governmental sector (including SOEs) or in foreign owned firms usually means higher social status and more social resources. In our sample, the parents who work in these two sectors account for $42.9 \%$ (father) and $35.4 \%$ (mother) in the urban group and only $18.7 \%$ (father) and $11.2 \%$ (mother) in the rural group, reflecting the disparity in yet another socio-economic dimension.

The rural households also lag behind with respect to environmental quality. Rural families' sanitary conditions are distinctively worse: only $51.8 \%$ and $16.3 \%$ rural households have access to improved drinking water (tap water) and in-house flush toilets, while this percentage is $87.6 \%$ and $47.2 \%$ in the urban sample. A comparison of the distance between household residence to the nearest health facility indicates that rural children on average live closer to a medical clinic than urban children $(0.37 \mathrm{~km}$ vs. $0.4 \mathrm{~km})$. However, this difference in distance is not matched by equal quality of health care accessible to children. In fact, higher ranked hospitals (those beyond the county level) account for a much higher share in the nearest health facilities as reported by the urban sample ( $48.3 \%$ vs $35.4 \%$ ), indicating that the urban residents are more likely to have access to better quality care. Lastly, the community smoking prevalence, a proxy measure for indoor air pollution is about the same in urban and rural areas (33.4\% vs. $33.6 \%)$ due to the large smoking population across the country.

\section{Empirical Results}

\subsection{Benchmark Model Estimates}


In the benchmark model, we estimate equation (1) by OLS on the urban and rural samples, and report the results in Tables $2 \mathrm{~A}$ and $2 \mathrm{~B}$, respectively. For both samples, the coefficient estimates of the two key variables, MHealth and FHealth, are significant and positive in all models, indicating a positive effect of parents' health on their children's health as measured by height-for-age z scores [columns (1) - (3)] and weight-for-age z scores [columns (4) - (6)]. Introduction of the additional control variables, i.e., socio-economic factors $\mathrm{W}_{i t}$ [in column (2) and (5)] leads to reduction in the estimated impact of parental health on child height, but adding environmental characteristics $\mathrm{E}_{i t}$ and the health care related variables $\mathrm{H}_{i t}$ [in column (3) and (6)] does not have further effects on the statistical significance nor the magnitude of the intergenerational elasticity estimates. These results imply a strong intergenerational health transmission in China among both the urban and rural families. The implied transmission elasticity is $6.05-11.67$ for height measures and $1.94-4.61$ for weight measures. A comparison of the estimates for the two sub-samples (Tables 2A and 2B) suggests that the parent-to-offspring health (particularly height) transmission is stronger in rural China, and that the impacts of mother's education and household per capita income on child health is also stronger in the rural areas. This indicates a difference in the equality of opportunity between the two sectors (section 5.3 will explore this inequality in more detail).

\section{[Insert Table 2A and 2B about Here]}

We next turn to the estimates of the control variables. Among the basic demographic characteristics, age has a significant and U-shaped effect on children's health status, with the estimated turning point at around age 8 . The better development outcomes for younger children before this age may be a result of continued improvements in feeding practices and nutrition intake of newborns during the recent decade. Parental demographic variables (such as the age of father and mother) also have a significant impact on their children's health outcomes. Moreover, the region fixed effect is also evident: children living in the Eastern (Central) provinces are much healthier than those in Central (Western) China. This regional inequality in health is consistent with the uneven distribution of economic activities in China, where Eastern, coastal provinces have enjoyed rapid economic development since the 1980's, whereas the Western inland regions lag behind, resulting in unequal access to nutrition and other health care resources for children. 
The parental socio-economic variables shed light on the impact of parental accumulation of financial capital (wealth), human capital (education) and social capital (employment rank) on the children's health, for which prior literature on health determination documented mixed evidence (Adams et.al, 2003; Adda, 2003; Currie, 1999; Cutler et al., 2011). In our study, the household income is found to have a positive influence on children's health. The impact is stronger in rural areas, with an estimated semi-elasticity of $0.069 \%$ on height-for-age z scores and $0.038 \%$ on weight-for-age $\mathrm{z}$ scores. The effect of parents' educational attainment is more mixed. The coefficient estimates of father's education are mostly insignificant, whereas the mother's education seems to play a more important role for their offspring's health (most likely because mothers spend disproportionally more time with their children than fathers). In the urban areas, mothers with a college degree or above tend to have much healthier children compared to those with no formal schooling (the reference category), with a marginal effect of 0.53 on the weight-for-age $\mathrm{z}$ scores. In the rural areas, due to the relatively small sample size of college graduates, the most significant impact is from the middle school education: women who completed junior / senior high schools are found to have children with better health (marginal effects being 0.12 and 0.14 on height and weight $\mathrm{z}$ scores respectively). The parental education effect verifies the importance of nurturing factors in children's early age development. Another often ignored SES dimension parents' social capital accumulation, which is indicated by parents' employment status. Here mothers' job choices again play a more important role relative to fathers: the rural mothers working for government or SOEs are found to have significantly healthier children (with respect to both the height and weight $\mathrm{z}$ scores), while those working in a farm or collective enterprises tend to have children with poorer health outcomes. To the extent that occupations in government, SOEs or foreign enterprises represent higher social status, these findings indicate the impact of social capital on the offspring's health.

Prior studies also suggest that environmental conditions such as water sanitation and air pollution can play a vital role in adults' and children's health (Lee, Rosenzweig and Pitt, 1997; Chay and Greenstone, 2005). This is reflected by the environmental variables (flush, tap, smoke) in columns (3) and (6). However, the coefficient estimates of these variables mostly do not differ significantly from zero (this is also the case for healthcare accessibility variable, $h f d i s$ ), although in general their signs are positive. This suggests that the potentially positive influences of 
environmental factors are moderated by the impacts of parents' health and socio-economic factors.

\subsection{Random Effects Model Estimates}

As discussed in section 3.2, unobserved family traits such as genetic characteristics and lifestyle choices can affect the health of both parents and their children and hence give rise to endogeneity bias in the benchmark estimation. To eliminate the impact of such family specific and time-invariant heterogeneity, we exploit the longitudinal nature of CHNS data and apply the random effects model on the (unbalanced) panel of 7,363 parent-offspring pairs in our sample. The quasi-demeaned transformation in RE models allows us to obtain consistent estimates of the intergenerational transmission elasticity controlling for such family fixed effects. The estimation results are given in Table 3.

\section{[Insert Table 3 about Here]}

As in the benchmark model, the parental health variables in Table 3 attach significant and positive coefficient estimates in both the urban and rural samples and with respect to both height and weight outcomes. This indicates that our findings on the parent-to-offspring health transfer are robust to the elimination of unobserved family heterogeneity ${ }^{16}$ Compared with Tables $2 \mathrm{~A}$ and $2 \mathrm{~B}$, the magnitude of the transmission stays about the same for mothers but is slightly lower for fathers, suggesting that the family heterogeneity is likely to correlate positively with the parents' and children's health. Furthermore, the signs and statistical significance of other control variables (such as the demographic, socio-economic and environmental characteristics) are also in line with the benchmark model. Notably, better health outcomes are observed among children in Eastern regions, and in families with higher income and better educated / employed mothers. Controlling for the household fixed effects, access to health care services also play a significant role in determining children's health: children living closer to a hospital are found to have better (poorer) weight outcomes in the urban (rural) sample; the discrepancy is partially due to the rank and quality difference of health care facilities between the two sectors (see section 4.2).

\footnotetext{
${ }^{16} \mathrm{We}$ also estimated a corresponding RE model with individual level heterogeneity, and obtained similar results.
} 


\section{3 Blinder-Oaxaca Decomposition Results}

The Blinder-Oaxaca decomposition examines the underlying driving forces of the health inequality between urban and rural children by categorizing the overall disparity in children's height-for-age and weight-for-age $\mathrm{z}$ scores into two components: the endowment effect which represents the observed differences in parental characteristics such as health, socio-economic status, living environment and access to health care; and the discrimination effect which represents the unobserved differences in the impact of the above parent characteristics on children's health outcomes. Table 4 suggests that both effects are statistically significant in explaining the overall disparity in children's health. Of the overall urban-rural inequality $(0.345$ in height-for-age z scores and 0.236 in weight-for-age z scores), the "endowed disparity" from parents' characteristics accounts for about 59\% and 48\% for children's height and weight outcomes respectively, and the remaining gap is attributable to the discrimination effect. This means that a large portion of children's health inequality can be explained by the health and non-health endowment from their parents. Thus, the labor mobility restrictions due to the hukou regime and the associated urban-rural inequality in income, health, education and environment can have a long lasting impact on not only the current generation's quality of life, but also the accumulation of human capital of the offspring generations.

\section{[Insert Table 4 about Here]}

Next, in order to identify the detailed sources of the health disparity, we further decompose the endowment effect into the following components: parental health (MHealth ${ }_{i t}$ and FHealth ${ }_{i t}$ ), parental socioeconomic status (income, education, employment), household environment, access to health care, demographic variables (child age and sex, parent age), and other factors (year and region fixed effects). According to the middle section of Table 4, parents' health and their socio-economic status account for a dominant share of the total endowment effect. For example, parental health accounts for $25 \%$ of the endowed disparity in children's height-for-age z scores and 56\% in weight-for-age z scores. Parental income, education and employment status jointly account for $75 \%$ and $96 \%$ of the endowment effect in the height and weight measures. This result implies that the majority of the overall inequality in children's health $(59 \%$ and $73 \%$ of the overall inequality in height and weight) is attributable to parents' health and socio-economic 
factors, while the direct parent-to-offspring transmission of health accounts for $15 \%$ and $27 \%$, respectively. In other words, if the rural parents were as healthy as the urban ones, the differences in their offspring's health status would be reduced by $15 \%$ to $27 \%$ due to the direct (or endowed) intergenerational health inequality.

On the other hand, the discrimination effect reflects the urban-rural disparity in the elasticity of health transmission, and can be considered as the indirect intergenerational health inequality. In the bottom section of Table 4, we decompose the total discrimination effect into more detailed components, and find that most of the categorized discrimination effects are not statistically significant. This means that although the impact of parental characteristics on children's health is potentially heterogeneous between the urban and rural sectors (it accounts for $42 \%$ and $52 \%$ of the overall urban-rural disparity in height and weight $\mathrm{z}$ scores), the impact of each vector (particularly health and socio-economic status) does not differ significantly between the two sectors. Overall, the results of the Blinder-Oaxaca decomposition imply that the disparity in parental health is an important determinant of the difference in their offspring's health, supporting the hypothesis of intergenerational health inequality in China.

\subsection{Nature-Nurture Interactions}

Next, we turn to the interactions between "nature" and "nurture" and explore their role in the intergenerational health transmission. As discussed in section 3.4, heritable genetic traits such as height and weight are traditionally deemed as pure natural endowments, but have in recent medical studies been found to correlate with "nurturing" factors reflecting individual choices (Currie, 2011). Specifically, the epigenome switches that determine gene expression through inheritance can be triggered by environmental factors, and thus parents' behaviors and choices can have a long-lasting impact on their offspring's health. If parents with better health choose to live in a "cleaner" environment or engage in healthier lifestyles, then the above mentioned intergenerational health transmission will be amplified by the nature-nurture interactions, as part of the parents' health capital is transferred to their offspring through the behavioral channel.

[Insert Table 5 about Here]

Table 5 reports the estimated nature-nurture interactions in China for the urban and rural 
samples. Each column has an outcome variable that represents one particular nurturing factor, and our focus is on the coefficients of parent health indicators, i.e. $\beta_{m}$ and $\beta_{f}$ in equation (5). As shown in column (1) - (5), parent health has significant and positive effect on all socio-economic dimensions in both the urban and rural regressions. For example, healthier fathers and mothers (indicated by their height measures) tend to have higher income, higher educational attainment (measured by years of schooling) and higher ranked employment (measured by government, SOE or foreign sector jobs).

Similarly, results in column (8) - (10) indicate that in both urban and rural families, parents with better health are more likely to live in a cleaner environment with improved drinking water, less indoor air pollution and better overall household hygiene. The results on health care related variables [column (11)] are less pronounced: the correlation between parents' health and the access to health care services (measured by distance between residential locations to the nearest hospital) is not statistically significant. This may be due to the difference between the nearest health facilities and the facilities parents actually used during the prenatal or nursing periods. Overall, the above findings suggest that there is a positive correlation between parents' health and their socio-economic status and environmental choices in China, thus health is likely to be transmitted across generations through several "nurturing" channels. The results support the "nature-nurture interaction" hypothesis, and imply that the intergenerational health transmission in China may be intensified by such interaction. Moreover, a comparison of the coefficient estimates in Table 5 also suggests the interaction is stronger in the urban sector, i.e. healthier parents in the cities are more likely to provide a better nurturing environment to their children. This, in turn, tends to exacerbate the urban-rural health inequality in China.

\section{Conclusions}

As is well known, the Chinese economy is characterized by a high, and for almost three decades increasing, income inequality and recent research has, moreover, demonstrated that this is accompanied by a high degree of inequality of opportunity. The mechanisms giving rise to the high intergenerational income persistency is not well understood, but education and health are two factors often mentioned in the discussion. In this paper, we have examined the 
intergenerational inequality of health in China, focusing on children's health and the extent to which poor health is transmitted from one generation to the next. Our econometric analyses show that parental health is strongly correlated with their offspring's health after controlling for parents' socio-economic status (education, income and type of employment), demographic traits of parents and their children, environmental and health care factors, and unobserved household heterogeneity.

A considerable part of income inequality in China reflects the large income differences between urban and rural areas. This disparity is also present in children's health. According to our decomposition analysis, the bulk of the urban-rural child health differential is due to differences in urban and rural parents' education and income, but differences in parents' health also play a significant role. Thus, if there were no disparities between urban and rural parents' health, the inequality in their children's health would be reduced by 15-27 percent. We also find that nurture factors (environment) are strongly correlated with nature factors, providing support to the notion that nature and nurture factors interact. These interactions are likely to amplify the intergenerational transmission of health.

Improving the health of its population and reducing the urban-rural disparity in health are one of the major challenges for China. Our study has shown that differences in children's health are largely explained by differences in parental socio-economic status and that the urban-rural health differential also reflects these differences. This implies that the increasing inequality of income and opportunity in China can be ameliorated through the improvement of the current generation's health status and living standards. In particular, policies aiming at a reduction of the influence of parents' socio-economic resources on their offspring's health would not only lead to improvements in health in general, but also contribute to a reduction of the urban-rural health gap. Studies have shown that poor child health has strong negative effects on children's performance in early school years ${ }^{17}$ (especially in the rural areas) and hence their future accumulation of human capital. Consequently, this type of policies will have important spillover effects into the labor market.

\footnotetext{
${ }^{17}$ See e.g., Luo, Shi, Zhang, Liu, Rozelle, Sharbono, Yue, Zhao and Martorell (2012) and Shi, Chang, Su, Luo, Zhang and Rozelle (2012).
} 


\section{References}

[1]. Adams, P., M. Hurd, D. McFadden, A. Merrill and T. Ribeiro (2003), "Healthy, Wealthy, and Wise? Tests for Direct Causal Paths between Health and Socioeconomic Status", Journal of Econometrics, 112, 3-56

[2]. Adda, J, Chandola, T and Marmot, M (2002), "Socio-Economic Status and Health: Causality and Pathways", Journal of Econometrics, 112, 57 - 63

[3]. Akbulut, M. and A. Kugler (2007), Intergenerational Transmission of Health Status in the U.S. among Natives and Immigrants. University of Houston, Department of Economics, mimeo

[4]. Almond, D. and J. Currie (2010), "Human Capital Development before Age Five", in O. Ashenfelter and D. Card (eds.), Handbook of Labor Economics, Volume 4B, 1315-1486

[5]. Almond, D., L. Edlund, H. Li and J. Zhang (2010), "Long-term Effects of the 1959-61 China Famine: Mainland China and Hong Kong", in T. Ito and A. Rose (eds.), The Economic Consequences of Demographic Change in East Asia. University of Chicago Press, $321-350$

[6]. Banzhaf H. and R. Walsh (2008), "Do People Vote with Their Feet? An Empirical Test of Tiebout”, American Economic Review, 98, 843-863

[7]. Becker, G. and N. Tomes (1979), “An Equilibrium Theory of the Distribution of Income and Intergenerational Mobility", Journal of Political Economy, 87, 1153-1189

[8]. Bhalotra, S. and S. Rawlings (2013), "Gradients of the Intergenerational Transmission of Health in Developing Countries", Review of Economics and Statistics, 95, 660-672

[9]. Björklund, A., T. Eriksson, M. Jäntti, O. Raaum and E. Österbacka (2002), "Brother Correlations in Earnings in Denmark, Finland, Norway and Sweden Compared to the United States", Journal of Population Economics, 15, 757-772

[10].Björklund, A. and M. Jäntti (2009), "Intergenerational Mobility and the Role of Family Background", in: W. Salwerda, B. Nolan and T. Smeeding (eds.), Oxford Handbook of Economic Inequality, 491-521. Oxford: Oxford University Press

[11].Björklund, A. and M. Jäntti (2012), "How Important Is Family Background for Labor-Economic Outcomes?”, Labour Economics, 19, 465-474

[12].Björklund, A. and K. Salvanes (2011), "Education and Family Background: Mechanisms 
and Policies", in: E. Hanushek, S. Machin and L. Voessmann (eds.), Handbook of Economics of Education, Volume 3, 201-247. Amsterdam: Elsevier

[13].Black, S. and P. Devereux (2011), "Recent Developments in Intergenerational Mobility”, in: O. Ashenfelter and D. Card (eds.), Handbook of Labor Economics, Vol. 4, Part B, 1487-1541. New York: Elsevier

[14].Blanden, J., P. Gregg and L. Macmillan (2007), “Accounting for Intergenerational Income Persistence: Noncognitive Skills, Ability and Education”, Economic Journal, 117: C43-60

[15].Blinder, A. (1973), "Wage Discrimination: Reduced Form and Structural Variables", Journal of Human Resources, 8, 436-455.

[16].Bowblis, J., H. Meng, and K.Hyer, (2013) "The Urban-Rural Disparity in Nursing Home Quality Indicators: The Case of Facility-Acquired Contractures”, Health Services Research, $2,47-69$

[17].Bowles, S., H. Gintis and M. Groves (2005), "Introduction", in S. Bowles, S. Gintis and M. Growes (eds.), Unequal Chances: Family Background and Economic Success. New York: Russell Sage and Princeton University Press

[18].Bowles, S., H. Gintis and M. Osborne (2001), "The Determinants of Earnings: A Behavioral Approach”, Journal of Economic Literature, 39, 1137-1176

[19].Case, A., A. Fertig and C. Paxson (2005), "The Lasting Impact of Childhood Health and Circumstance", Journal of Health Economics, 24, 365-389

[20]. Chay, Kenneth and M. Greenstone (2005), "Does Air Quality Matter? Evidence from the Housing Market", Journal of Political Economy, 113, 376-424

[21].Chen, Y., and Li, H. (2009), "Mother's Education and Child Health: Is There a Nurturing Effect?”, Journal of Health Economics, 28, 413-26

[22].Chen, Y., Xiaoyan, L. and L. Zhou (2010), Child Health and the Income Gradient: Evidence from China, IZA Discussion Paper No. 5182

[23].Chen, Y. and L. Zhou (2007), "The Long-Term Health and Economic Consequences of the 1959-1961 Famine in China”, Journal of Health Economics, 26, 659-681.

[24].Corak, M. (2013), "Inequality from Generation to Generation: the United States in Comparison", in: R. Rydcroft (ed.), The Economics of Inequality, Poverty and Discrimination in the 21st Century. Santa Barbara, CA: ABC-CLIO 
[25].Currie, J. (2009), "Healthy, Wealthy, and Wise: Socioeconomic Status, Poor Health in Childhood, and Human Capital Development”, Journal of Economic Literature, 47, 87-122 [26].Currie, J. (2011), "Inequality at Birth: Some Causes and Consequences", American Economic Review, 101, 1-22

[27].Currie, J. and E. Moretti (2003), “Mother's Education And The Intergenerational Transmission of Human Capital: Evidence From College Openings”, The Quarterly Journal of Economics, 118, 1495-1532

[28].Currie, J. and E. Moretti (2007), "Biology as Destiny? Short- and Long-run Determinants of Intergenerational Transmission of Birth Weight”, Journal of Labor Economics, 25, 231-264

[29].Currie, J. and M. Neidell (2005), "Air Pollution and Infant Health: What Can We Learn From California's Recent Experience?” Quarterly Journal of Economics, 120(3),1003-1030

[30].Currie, J. and Rosemary H. (1999), "Is the Impact of Shocks Cushioned by Socioeconomic Status? The Case of Low Birth Weight”, American Economic Review, 89, 245-250

[31].Currie, J. and T. Vogl (2013), "Early-Life Health and Adult Circumstance in Developing Countries", Annual Review of Economics, 5, 1-36

[32].Cutler, D., A. Lleras-Muney, and T. Vogl (2011), "Socioeconomic Status and Health: Dimensions and Mechanisms", in S. Glied and P. Smith (eds.), Oxford Handbook of Health Economics

[33].Deaton, A. (2003), "Health, Inequality, and Economic Development", Journal of Economic Literature, $41,133-158$

[34].Dohmen, T., A. Falk, D. Huffman and U. Sunde (2012), "The Intergenerational Transmission of Risk and Trust Attitudes”, Review of Economic Studies, 79, 1-33

[35].Dunn, C. (2007), “The Intergenerational Transmission of Lifetime Earnings: Evidence from Brazil”, B.E. Journal of Economic Analysis \& Policy, 7(2), doi:10.2202/1935-1682.1782

[36].Eriksson, T., B. Bratsberg and O. Raaum (2005), Earnings Persistence across Generations: Transmission through Health? Memorandum 35/2005, Oslo University, Department of Economics

[37].Eriksson, T. and Y. Zhang (2012), "The Role of Family Background for Earnings in Rural China”, Frontiers of Economics in China, 7, 466-478

[38].Ermisch, J., M. Jäntti and T. Smeeding (eds.) (2012), From Parents to Children. The 
Intergenerational Transmission of Advantage. New York: Russell Sage Foundation

[39].Gao, J., S. Tang, R. Tolhurst, and K. Rao (2001), "Changing Access to Health Services in Urban China: Implications for Equity”, Health Policy and Planning, 16, 302-312

[40].Gong, C., A. Leigh and X. Meng (2012), "Intergenerational Income Mobility in Urban China”, Review of Income and Wealth, 58, 481-503

[41].Gorgens, T., M. Xin and R. Vaithianathan (2012), "Stunting and Selection Effects of Famine: A Case Study of the Great Chinese Famine”, Journal of Development Economics, 97, $99-111$

[42].Grawe, N. (2004), "Intergenerational Mobility for Whom? The Experience of High and Low Earning Sons in International Perspective”, in M. Corak (ed.), Generational Income Mobility in North America and Europe. Cambridge, MA: Cambridge University Press, $58-89$

[43]. Greene W.H, (2011). Econometric analysis ( $7^{\text {th }}$ ed). Prentice Hall.

[44].Hertz, T., T. Jayasundera, P. Piraino, S. Selcuk, N. Smith and A. Verashchagina (2008), "The Inheritance of Educational Inequality: International Comparisons and Fifty-Year Trends", B.E. Journal of Economic Analysis \& Policy, 7(2), doi: 10.2202/1935-1682.1775

[45].Jann B. (2005), Standard Errors for the Blinder-Oaxaca Decomposition. 3rd Verman Stata Users Group Meeting, Berlin

[46].Johnson R. and R. Schoeni (2011), “The Influence of Early-Life Events on Human Capital, Health Status, and Labor Market Outcomes over the Life Course.” The B. E. Journal of Economic Analysis \& Policy, 11(3), 3-57

[47].Lee, L., M. Rosenzweig and M. Pitt (1997), "The Effects of Improved Nutrition, Sanitation, and Water Quality on Child Health in High Mortality Populations.”, Journal of Econometrics, 77, 209-35

[48].Lefgren, L., M. Lindquist and D. Sims (2012), "Rich Dad, Smart Dad: Decomposing the Intergenerational Transmission of Income”, Journal of Political Economy, 120, 268-303

[49].Lien D. and W. Evans (2005), "Estimating the Impact of Large Cigarette Tax Hikes: The Case of Maternal Smoking and Infant Birth Weight.” Journal of Human Resources, XL(2), 373-392

[50].Liu, H., H. Fang and Z. Zhao (2012), Urban-Rural Disparities of Child Health and 
Nutritional Status in China from 1989 to 2006. IZA Discussion Paper No. 6528

[51].Liu, Y., W. Hsiao and K. Eggleston (1999), "Equity in Health and Health Care: The Chinese Experience", Social Science and Medicine, 41, 1085-1093

[52].Luo, R., Y. Shi, L. Zhang, C. Liu, S. Rozelle, B. Sharbono, A. Yue, Q. Zhao and R. Martorell (2012), "Nutrition and Educational Performance in Rural China's Elementary Schools: Results of a Randomized Control Trial in Shaanxi Province", Economic Development and Cultural Change, 60, 735-772

[53].Mangyo, E. (2008), "The Effect of Water Accessibility on Child Health in China.”, Journal of Health Economics, 27, 1343-56

[54].Meng, X. and N. Qian (2009), The Long Term Consequences of Famine of Survivors: Evidence from China's Great Famine. NBER WP 14917

[55].Morduch J., and T. Sicular (2002), "Rethinking Inequality Decomposition, with Evidence from Rural China”, Economic Journal, 112, 93-106

[56].Nilsson, P. (2008) 'Does A Pint A Day Affect Your Child's Pay? The Effect of Prenatal Alcohol Exposure on Adult Outcomes", Centre for Microdata Methods and Practice Working Paper CWP 22/08, The Institute for Fiscal Studies

[57].Oaxaca, R. (1973), "Male-Female Wage Differentials in Urban Labor Markets", International Economic Review, 14, 693-709

[58].Quheng, D., B. Gustafsson and L. Shi (2013), "Intergenerational Income Persistency in Urban China", Review of Income and Wealth, 59, 416-436

[59].Shi, Y., F. Chang, X. Su, R. Luo, L. Zhang and S. Rozelle (2012), "Parental Training, Anemia, and the Impact on the Nutrition of Female Students in China's Poor Rural Elementary Schools", China Agricultural Economic Review, 4, 151-167

[60].Shi L. and T. Sicular, eds. (2012), Rising Inequality in China: Public Policy and the Pursuit of a Harmonious Society. New York: Cambridge University Press

[61].Smith J., Y. Shen, J. Strauss, Z. Yang and Y. Zhao (2012), "The Effects of Childhood Health on Adult Health and SES in China", Economic Development and Cultural Change, 61, $127-156$

[62].Solon, G. (1992), "Intergenerational Income Mobility in the United States", American Economic Review, 82, 393-408 
[63].Solon, G. (1999), "Intergenerational Mobility in the Labor Market", in: O. Ashenfelter and D. Card (eds.), Handbook of Labor Economics, Vol. 3, Part A, 1761-1800. New York: Elsevier

[64].Strauss J. and D. Thomas (1998), "Health, Nutrition and Economic Development", Journal of Economic Literature, 36, 766-817

[65].Thomas, D., V. Lavy, J. Strauss (1991), Public Policy and Anthropometric Outcomes in the Cote d'Ivoire. Yale - Economic Growth Center.

[66]. World Health Organization (1995). Physical Status: the Use and Interpretation of Anthropometry. WHO Technical Report Series No.854.

[67].Zhang, Y. and T. Eriksson (2010), "Inequality of Opportunity and Income Inequality in Nine Chinese Provinces, 1989-2006”, China Economic Review, 21, 607-616

[68].Zimmermann, D. (1992), "Regression toward Mediocrity in Economic Stature", American Economic Review, 82, 409-429 
Table 1 Sample Descriptive Statistics of Selected Variables

\begin{tabular}{|c|c|c|c|c|}
\hline \multirow[t]{2}{*}{ Variable } & \multirow[t]{2}{*}{ Definition } & Full sample & Urban & Rural \\
\hline & & (1) & (2) & (3) \\
\hline \multirow[t]{2}{*}{ hzscore } & Height z score of child & -0.976 & $-0.729 *$ & -1.071 \\
\hline & & $(1.225)$ & $(1.246)$ & (1.204) \\
\hline \multirow[t]{2}{*}{ wzscore } & Weight z score of child & -0.568 & $-0.371 *$ & -0.640 \\
\hline & & (1.190) & $(1.218)$ & (1.172) \\
\hline \multirow[t]{2}{*}{ heightm } & Mother's height (cm) & 155.744 & $156.100 *$ & 155.609 \\
\hline & & $(5.800)$ & $(5.969)$ & (5.729) \\
\hline \multirow[t]{2}{*}{ heightf } & Father's height $(\mathrm{cm})$ & 166.306 & $166.851^{*}$ & 166.097 \\
\hline & & $(6.361)$ & $(6.754)$ & (6.191) \\
\hline \multirow[t]{2}{*}{ weightm } & Mother's weight (kg) & 54.293 & $55.367^{*}$ & 53.886 \\
\hline & & $(8.444)$ & $(8.564)$ & $(8.362)$ \\
\hline \multirow[t]{2}{*}{ weightf } & Father's weight (kg) & 61.901 & $63.366^{*}$ & 61.341 \\
\hline & & (9.755) & $(10.310)$ & $(9.476)$ \\
\hline \multirow[t]{2}{*}{ age } & Child's age (year) & 9.877 & $10.066^{*}$ & 9.806 \\
\hline & & $(4.780)$ & $(4.816)$ & $(4.764)$ \\
\hline \multirow[t]{2}{*}{ female } & Child's gender (female $=1$ ) & 0.467 & $0.484^{*}$ & 0.461 \\
\hline & & (0.499) & $(0.500)$ & (0.499) \\
\hline \multirow[t]{2}{*}{ agem } & Mother's age (year) & 36.357 & 36.452 & 36.321 \\
\hline & & $(6.655)$ & $(6.483)$ & (6.718) \\
\hline \multirow[t]{2}{*}{ agef } & Father's age (year) & 38.017 & $38.576^{*}$ & 37.807 \\
\hline & & (7.165) & $(6.937)$ & (7.238) \\
\hline \multirow[t]{2}{*}{ east } & live in eastern China & 0.270 & $0.241^{*}$ & 0.285 \\
\hline & & $(0.444)$ & $(0.427)$ & 0.452 \\
\hline \multirow[t]{2}{*}{ middle } & live in central China & 0.432 & 0.437 & 0.438 \\
\hline & & $(0.495)$ & $(0.496)$ & 0.496 \\
\hline \multirow[t]{2}{*}{ prif } & Primary school (father) & 0.261 & $0.176^{*}$ & 0.293 \\
\hline & & $(0.439)$ & $(0.381)$ & $(0.455)$ \\
\hline \multirow[t]{2}{*}{ juf } & Middle school (father) & 0.427 & $0.408^{*}$ & 0.433 \\
\hline & & $(0.495)$ & (0492) & $(0.496)$ \\
\hline \multirow[t]{2}{*}{ senf } & High school (father) & 0.211 & $0.264^{*}$ & 0.191 \\
\hline & & $(0.408)$ & $(0.441)$ & $(0.393)$ \\
\hline \multirow[t]{2}{*}{ colf } & College or above (father) & 0.035 & $0.085^{*}$ & 0.015 \\
\hline & & $(0.183)$ & $(0.280)$ & $(0.123)$ \\
\hline \multirow[t]{2}{*}{ prim } & Primary school (mother) & 0.299 & $0.226^{*}$ & 0.326 \\
\hline & & $(0.458)$ & $(0.418)$ & $(0.469)$ \\
\hline \multirow[t]{2}{*}{ jum } & Middle school (mother) & 0.337 & $0.360^{*}$ & 0.329 \\
\hline & & $(0.473)$ & $(0.480)$ & $(0.470)$ \\
\hline \multirow[t]{2}{*}{ senm } & High school (mother) & 0.149 & $0.235^{*}$ & 0.117 \\
\hline & & $(0.356)$ & $(0.424)$ & $(0.321)$ \\
\hline \multirow[t]{2}{*}{ colm } & College or above (mother) & 0.020 & $0.054^{*}$ & 0.007 \\
\hline & & $(0.138)$ & $(0.226)$ & $(0.081)$ \\
\hline farmf & Farmer (father) & 0.090 & $0.046^{*}$ & 0.107 \\
\hline
\end{tabular}




\begin{tabular}{|c|c|c|c|c|}
\hline & & $(0.287)$ & $(0.210)$ & $(0.309)$ \\
\hline \multirow[t]{2}{*}{ collf } & Collective enterprise (father) & 0.468 & $0.290^{*}$ & 0.535 \\
\hline & & $(0.499)$ & $(0.454)$ & $(0.499)$ \\
\hline \multirow[t]{2}{*}{ govef } & Government or SOE (father) & 0.251 & $0.424 *$ & 0.186 \\
\hline & & $(0.434)$ & $(0.494)$ & $(0.389)$ \\
\hline \multirow[t]{2}{*}{ privf } & Private enterprise (father) & 0.094 & 0.101 & 0.091 \\
\hline & & $(0.287)$ & $(0.302)$ & $(0.288)$ \\
\hline \multirow[t]{2}{*}{ foref } & Foreign enterprise(father) & 0.002 & $0.005^{*}$ & 0.001 \\
\hline & & $(0.049)$ & $(0.072)$ & $(0.037)$ \\
\hline \multirow[t]{2}{*}{ farmm } & Farmer (mother) & 0.096 & $0.050^{*}$ & 0.114 \\
\hline & & $(0.295)$ & $(0.218)$ & $(0.318)$ \\
\hline \multirow[t]{2}{*}{ collm } & Collective enterprise (mother) & 0.486 & $0.305^{*}$ & 0.555 \\
\hline & & $(0.500)$ & $(0.460)$ & $(0.497)$ \\
\hline \multirow[t]{2}{*}{ govem } & Government or SOE (mother) & 0.174 & $0.344^{*}$ & 0.111 \\
\hline & & $(0.379)$ & $(0.475)$ & $(0.314)$ \\
\hline \multirow[t]{2}{*}{ privm } & Private enterprise (mother) & 0.060 & $0.073^{*}$ & 0.056 \\
\hline & & $(0.240)$ & $(0.261)$ & $(0.230)$ \\
\hline \multirow[t]{2}{*}{ forem } & Foreign enterprise(mother) & 0.004 & $0.010^{*}$ & 0.001 \\
\hline & & $(0.061)$ & $(0.102)$ & $(0.033)$ \\
\hline \multirow[t]{2}{*}{ income } & Household per cap income (Yuan) & 2766.508 & $3886.701^{*}$ & 2431.819 \\
\hline & & $(2.632)$ & $(2.606)$ & $(2.560)$ \\
\hline \multirow[t]{2}{*}{ tap } & Tap water in household (1=yes) & 0.616 & $0.876^{*}$ & 0.518 \\
\hline & & $(0.486)$ & $(0.330)$ & $(0.500)$ \\
\hline \multirow[t]{2}{*}{ flush } & Flush toilet in household (1=yes) & 0.248 & $0.472^{*}$ & 0.163 \\
\hline & & $(0.432)$ & $(0.499)$ & $(0.369)$ \\
\hline \multirow[t]{2}{*}{ smokep } & Community smoking prevalence (\%) & 0.335 & 0.334 & 0.336 \\
\hline & & $(0.081)$ & $(0.080)$ & $(0.081)$ \\
\hline \multirow[t]{2}{*}{ hfdis } & Distance of nearest health care facility & 0.385 & 0.403 & 0.377 \\
\hline & $(\mathrm{km})$ & $(0.919)$ & $(0.857)$ & $(0.940)$ \\
\hline \multirow[t]{2}{*}{ hfrank } & Rank of nearest health care facility & 0.399 & $0.483^{*}$ & 0.354 \\
\hline & (1=beyond county level) & $(0.490)$ & $(0.500)$ & (0.478) \\
\hline Obs & Sample size & 16057 & 4398 & 11659 \\
\hline
\end{tabular}

Note: (1) The statistics reported are the sample mean with standard deviation in parenthesis. (2) Asterisks $\left({ }^{*}\right.$ ) denote statistically significant difference between the urban and rural groups (at $5 \%$ level). (3) The annual household per capita income is measured in 2009 yuan and is calculated by dividing the total household income by number of people in the family (parents and children). (4) The community smoking prevalence is defined as the number of smoking adults as a percentage of community population above 18 . 
Table 2A OLS Regression Results (Urban Sample)

\begin{tabular}{|c|c|c|c|c|c|c|}
\hline \multirow{3}{*}{ Variable } & \multicolumn{6}{|c|}{ Urban Sample } \\
\hline & \multicolumn{3}{|c|}{ hzscore } & \multicolumn{3}{|c|}{ wzscore } \\
\hline & (1) & (2) & (3) & (4) & (5) & (6) \\
\hline MHealth & $\begin{array}{c}0.048 * * * \\
(0.004)\end{array}$ & $\begin{array}{c}0.044^{* * *} \\
(0.004)\end{array}$ & $\begin{array}{c}0.046 * * * \\
(0.004)\end{array}$ & $\begin{array}{c}0.030 * * * \\
(0.003)\end{array}$ & $\begin{array}{c}0.026^{* * *} \\
(0.003)\end{array}$ & $\begin{array}{c}0.026^{* * *} \\
(0.004)\end{array}$ \\
\hline FHealth & $\begin{array}{c}0.051^{* * *} \\
(0.005)\end{array}$ & $\begin{array}{c}0.045^{* * *} \\
(0.005)\end{array}$ & $\begin{array}{c}0.044^{* * *} \\
(0.005)\end{array}$ & $\begin{array}{c}0.027^{* * *} \\
(0.004)\end{array}$ & $\begin{array}{c}0.026 * * * \\
(0.004)\end{array}$ & $\begin{array}{c}0.026 * * * \\
(0.004)\end{array}$ \\
\hline age & $\begin{array}{c}0.023 \\
(0.021)\end{array}$ & $\begin{array}{c}0.021 \\
(0.021)\end{array}$ & $\begin{array}{c}0.025 \\
(0.021)\end{array}$ & $\begin{array}{c}-0.233^{* * *} \\
(0.042)\end{array}$ & $\begin{array}{c}-0.233 * * * \\
(0.042)\end{array}$ & $\begin{array}{c}-0.228 * * * \\
(0.043)\end{array}$ \\
\hline $\operatorname{age}^{2}$ & $\begin{array}{l}-0.002 * \\
(0.001)\end{array}$ & $\begin{array}{l}-0.002 * \\
(0.001)\end{array}$ & $\begin{array}{l}-0.002 * \\
(0.001)\end{array}$ & $\begin{array}{c}0.015^{* * *} \\
(0.004)\end{array}$ & $\begin{array}{c}0.015^{* * *} \\
(0.004)\end{array}$ & $\begin{array}{c}0.014^{* * *} \\
(0.004)\end{array}$ \\
\hline female & $\begin{array}{l}-0.023 \\
(0.043)\end{array}$ & $\begin{array}{l}-0.036 \\
(0.043)\end{array}$ & $\begin{array}{l}-0.046 \\
(0.043)\end{array}$ & $\begin{array}{l}-0.039 \\
(0.054)\end{array}$ & $\begin{array}{l}-0.036 \\
(0.054)\end{array}$ & $\begin{array}{l}-0.044 \\
(0.055)\end{array}$ \\
\hline agef & $\begin{array}{l}0.014^{*} \\
(0.008)\end{array}$ & $\begin{array}{c}0.010 \\
(0.007)\end{array}$ & $\begin{array}{c}0.009 \\
(0.007)\end{array}$ & $\begin{array}{c}0.023^{* *} \\
(0.010)\end{array}$ & $\begin{array}{c}0.024^{* * *} \\
(0.009)\end{array}$ & $\begin{array}{l}0.024^{* *} \\
(0.009)\end{array}$ \\
\hline agem & $\begin{array}{c}0.005 \\
(0.009)\end{array}$ & $\begin{array}{c}0.007 \\
(0.008)\end{array}$ & $\begin{array}{c}0.007 \\
(0.008)\end{array}$ & $\begin{array}{c}-0.025^{* *} \\
(0.011)\end{array}$ & $\begin{array}{c}-0.023^{* *} \\
(0.011)\end{array}$ & $\begin{array}{c}-0.024^{* *} \\
(0.011)\end{array}$ \\
\hline east & $\begin{array}{c}0.413^{* * *} \\
(0.071)\end{array}$ & $\begin{array}{c}0.313^{* * *} \\
(0.072)\end{array}$ & $\begin{array}{c}0.344^{* * *} \\
(0.070)\end{array}$ & $\begin{array}{c}0.666^{* * *} \\
(0.086)\end{array}$ & $\begin{array}{c}0.502^{* * *} \\
(0.089)\end{array}$ & $\begin{array}{c}0.513^{* * *} \\
(0.089)\end{array}$ \\
\hline central & $\begin{array}{c}0.238 * * * \\
(0.060)\end{array}$ & $\begin{array}{c}0.183 * * * \\
(0.059)\end{array}$ & $\begin{array}{c}0.201^{* * *} \\
(0.058)\end{array}$ & $\begin{array}{c}0.386 * * * \\
(0.076)\end{array}$ & $\begin{array}{c}0.247 * * * \\
(0.075)\end{array}$ & $\begin{array}{c}0.262^{* * *} \\
(0.077)\end{array}$ \\
\hline prif & & $\begin{array}{c}0.078 \\
(0.191)\end{array}$ & $\begin{array}{c}0.021 \\
(0.189)\end{array}$ & & $\begin{array}{l}-0.161 \\
(0.198)\end{array}$ & $\begin{array}{l}-0.145 \\
(0.199)\end{array}$ \\
\hline juf & & $\begin{array}{c}0.206 \\
(0.192)\end{array}$ & $\begin{array}{c}0.128 \\
(0.189)\end{array}$ & & $\begin{array}{c}0.021 \\
(0.194)\end{array}$ & $\begin{array}{c}0.007 \\
(0.195)\end{array}$ \\
\hline senf & & $\begin{array}{c}0.105 \\
(0.196)\end{array}$ & $\begin{array}{c}0.043 \\
(0.192)\end{array}$ & & $\begin{array}{l}-0.134 \\
(0.196)\end{array}$ & $\begin{array}{l}-0.160 \\
(0.197)\end{array}$ \\
\hline colf & & $\begin{array}{c}0.300 \\
(0.209)\end{array}$ & $\begin{array}{c}0.255 \\
(0.206)\end{array}$ & & $\begin{array}{l}-0.035 \\
(0.227)\end{array}$ & $\begin{array}{l}-0.067 \\
(0.232)\end{array}$ \\
\hline prim & & $\begin{array}{c}-0.206^{* *} \\
(0.088)\end{array}$ & $\begin{array}{c}-0.212^{* *} \\
(0.089)\end{array}$ & & $\begin{array}{l}-0.023 \\
(0.137)\end{array}$ & $\begin{array}{l}-0.030 \\
(0.140)\end{array}$ \\
\hline jum & & $\begin{array}{l}-0.134 \\
(0.093)\end{array}$ & $\begin{array}{l}-0.144 \\
(0.093)\end{array}$ & & $\begin{array}{c}0.146 \\
(0.142)\end{array}$ & $\begin{array}{c}0.128 \\
(0.147)\end{array}$ \\
\hline senm & & $\begin{array}{l}-0.068 \\
(0.103)\end{array}$ & $\begin{array}{l}-0.094 \\
(0.104)\end{array}$ & & $\begin{array}{c}0.237 \\
(0.149)\end{array}$ & $\begin{array}{c}0.203 \\
(0.153)\end{array}$ \\
\hline colm & & $\begin{array}{l}-0.089 \\
(0.140)\end{array}$ & $\begin{array}{l}-0.162 \\
(0.140)\end{array}$ & & $\begin{array}{c}0.572^{* * *} \\
(0.192)\end{array}$ & $\begin{array}{c}0.531 * * * \\
(0.199)\end{array}$ \\
\hline farmf & & $\begin{array}{l}-0.087 \\
(0.141)\end{array}$ & $\begin{array}{l}-0.119 \\
(0.138)\end{array}$ & & $\begin{array}{l}-0.023 \\
(0.186)\end{array}$ & $\begin{array}{l}-0.053 \\
(0.187)\end{array}$ \\
\hline collf & & $\begin{array}{c}-0.078 \\
(0.087)\end{array}$ & $\begin{array}{l}-0.058 \\
(0.088)\end{array}$ & & $\begin{array}{l}-0.170 \\
(0.123)\end{array}$ & $\begin{array}{l}-0.169 \\
(0.126)\end{array}$ \\
\hline privf & & $\begin{array}{c}0.055 \\
(0.098)\end{array}$ & $\begin{array}{c}0.054 \\
(0.100)\end{array}$ & & $\begin{array}{l}-0.073 \\
(0.138)\end{array}$ & $\begin{array}{l}-0.094 \\
(0.143)\end{array}$ \\
\hline
\end{tabular}




\begin{tabular}{|c|c|c|c|c|c|c|}
\hline \multirow[t]{2}{*}{ govef } & & 0.020 & -0.002 & & -0.018 & -0.040 \\
\hline & & $(0.084)$ & $(0.085)$ & & $(0.112)$ & $(0.113)$ \\
\hline \multirow[t]{2}{*}{ foref } & & -0.126 & -0.104 & & 0.109 & 0.124 \\
\hline & & -0.087 & -0.119 & & -0.023 & -0.053 \\
\hline \multirow[t]{2}{*}{ farmm } & & 0.113 & 0.164 & & -0.115 & -0.083 \\
\hline & & $(0.127)$ & $(0.125)$ & & (0.174) & (0.176) \\
\hline \multirow[t]{2}{*}{ collm } & & -0.109 & -0.072 & & $-0.223 * *$ & $-0.201 * *$ \\
\hline & & $(0.072)$ & $(0.074)$ & & $(0.097)$ & $(0.100)$ \\
\hline \multirow[t]{2}{*}{ privm } & & $0.179 *$ & 0.140 & & 0.099 & 0.059 \\
\hline & & (0.095) & (0.097) & & $(0.132)$ & $(0.146)$ \\
\hline \multirow[t]{2}{*}{ govem } & & 0.080 & $0.121^{*}$ & & -0.108 & -0.062 \\
\hline & & $(0.071)$ & $(0.072)$ & & (0.089) & $(0.092)$ \\
\hline \multirow[t]{2}{*}{ forem } & & 0.261 & 0.187 & & -0.456 & $-0.558 *$ \\
\hline & & $(0.180)$ & $(0.186)$ & & $(0.287)$ & $(0.292)$ \\
\hline \multirow[t]{2}{*}{ Inincome } & & $0.047^{*}$ & $0.044^{*}$ & & 0.039 & 0.053 \\
\hline & & $(0.026)$ & $(0.026)$ & & $(0.032)$ & (0.033) \\
\hline \multirow[t]{2}{*}{ tap } & & & 0.052 & & & -0.005 \\
\hline & & & $(0.066)$ & & & $(0.088)$ \\
\hline \multirow[t]{2}{*}{ flush } & & & 0.071 & & & 0.018 \\
\hline & & & $(0.051)$ & & & $(0.065)$ \\
\hline \multirow[t]{2}{*}{ smokep } & & & 0.105 & & & -0.524 \\
\hline & & & $(0.293)$ & & & $(0.368)$ \\
\hline \multirow[t]{2}{*}{ hfdis } & & & 0.004 & & & 0.030 \\
\hline & & & $(0.020)$ & & & $(0.029)$ \\
\hline Year dummies & yes & yes & yes & yes & yes & yes \\
\hline Obs & 3,795 & 3,743 & 3,558 & 1,805 & 1,786 & 1,716 \\
\hline
\end{tabular}

Notes: (1) regressions are based on the urban data; sample size for wzscore regressions are smaller mainly because WHO only provides formulae for weight-for-age z scores for children age 10 or under. (2) $* * *, * *$ and $*$ denote statistical significance at $1 \%, 5 \%$ and $10 \%$ level, respectively; clustered standard errors (at household level) are reported in parentheses. (3) MHealth and FHealth denote mother's health (heightm, weightm) and father's health (heightf, weightf) indicators, which correspond to the child health indicators (hzscore, wzscore). 
Table 2B OLS Regression Results (Rural Sample)

\begin{tabular}{|c|c|c|c|c|c|c|}
\hline \multirow{3}{*}{ Variable } & \multicolumn{6}{|c|}{ Rural Sample } \\
\hline & \multicolumn{3}{|c|}{ hzscore } & \multicolumn{3}{|c|}{ wzscore } \\
\hline & (1) & (2) & (3) & (4) & (5) & (6) \\
\hline \multirow[t]{2}{*}{ MHealth } & $0.051 * * *$ & $0.046 * * *$ & $0.046^{* * *}$ & $0.025^{* * *}$ & $0.023 * * *$ & $0.024^{* * *}$ \\
\hline & $(0.003)$ & $(0.003)$ & $(0.003)$ & $(0.002)$ & $(0.002)$ & $(0.002)$ \\
\hline \multirow[t]{2}{*}{ FHealth } & $0.043 * * *$ & $0.039 * * *$ & $0.039 * * *$ & $0.029 * * *$ & $0.030 * * *$ & $0.030 * * *$ \\
\hline & $(0.003)$ & $(0.003)$ & $(0.003)$ & $(0.003)$ & $(0.003)$ & $(0.003)$ \\
\hline \multirow[t]{2}{*}{ age } & $0.024 * *$ & $0.023^{*}$ & $0.022^{*}$ & $-0.252 * * *$ & $-0.255^{* * *}$ & $-0.254 * * *$ \\
\hline & $(0.012)$ & $(0.012)$ & $(0.013)$ & $(0.025)$ & $(0.025)$ & $(0.026)$ \\
\hline \multirow[t]{2}{*}{ age $^{2}$} & $-0.001^{*}$ & $-0.001^{*}$ & $-0.001 *$ & $0.014 * * *$ & $0.015^{* * *}$ & $0.015^{* * *}$ \\
\hline & $(0.001)$ & $(0.001)$ & $(0.001)$ & $(0.002)$ & $(0.002)$ & $(0.002)$ \\
\hline \multirow[t]{2}{*}{ female } & -0.009 & -0.002 & -0.002 & $-0.129 * * *$ & $-0.120 * * *$ & $-0.121 * * *$ \\
\hline & $(0.028)$ & $(0.027)$ & $(0.028)$ & $(0.034)$ & (0.033) & $(0.034)$ \\
\hline \multirow[t]{2}{*}{ agef } & $0.009 *$ & 0.007 & 0.008 & -0.004 & $-0.011 * *$ & $-0.009 *$ \\
\hline & $(0.005)$ & $(0.005)$ & $(0.005)$ & $(0.005)$ & $(0.005)$ & $(0.005)$ \\
\hline \multirow[t]{2}{*}{ agem } & -0.003 & 0.003 & 0.003 & 0.008 & $0.014^{* *}$ & $0.013^{* *}$ \\
\hline & $(0.006)$ & $(0.006)$ & $(0.006)$ & $(0.006)$ & $(0.006)$ & $(0.006)$ \\
\hline \multirow[t]{2}{*}{ east } & $0.363^{* * *}$ & $0.330 * * *$ & $0.316^{* * *}$ & $0.640 * * *$ & $0.580 * * *$ & $0.546^{* * *}$ \\
\hline & $(0.046)$ & $(0.045)$ & $(0.047)$ & $(0.054)$ & $(0.054)$ & $(0.057)$ \\
\hline \multirow[t]{2}{*}{ central } & $0.193 * * *$ & $0.189 * * *$ & $0.171^{* * *}$ & $0.331 * * *$ & $0.312 * * *$ & $0.292 * * *$ \\
\hline & $(0.041)$ & $(0.040)$ & $(0.042)$ & $(0.048)$ & $(0.048)$ & $(0.050)$ \\
\hline \multirow[t]{2}{*}{ prif } & & 0.126 & 0.129 & & -0.215 & -0.192 \\
\hline & & $(0.091)$ & $(0.092)$ & & $(0.135)$ & $(0.137)$ \\
\hline \multirow[t]{2}{*}{ juf } & & 0.118 & 0.118 & & $-0.251^{*}$ & $-0.231^{*}$ \\
\hline & & $(0.095)$ & $(0.095)$ & & $(0.138)$ & $(0.139)$ \\
\hline \multirow[t]{2}{*}{ senf } & & 0.155 & 0.139 & & -0.157 & -0.136 \\
\hline & & $(0.100)$ & $(0.101)$ & & $(0.142)$ & $(0.142)$ \\
\hline \multirow[t]{2}{*}{ colf } & & $0.259 *$ & $0.260^{*}$ & & -0.138 & -0.057 \\
\hline & & 0.126 & 0.129 & & -0.215 & -0.192 \\
\hline \multirow[t]{2}{*}{ prim } & & 0.068 & 0.067 & & $-0.156^{* *}$ & $-0.180 * *$ \\
\hline & & $(0.048)$ & $(0.048)$ & & $(0.072)$ & $(0.072)$ \\
\hline \multirow[t]{2}{*}{ jum } & & $0.117^{* *}$ & $0.115^{* *}$ & & -0.036 & -0.070 \\
\hline & & $(0.053)$ & $(0.054)$ & & $(0.074)$ & $(0.074)$ \\
\hline \multirow[t]{2}{*}{ senm } & & $0.139 * *$ & $0.139 * *$ & & -0.077 & -0.103 \\
\hline & & $(0.066)$ & $(0.067)$ & & $(0.088)$ & $(0.088)$ \\
\hline \multirow[t]{2}{*}{ colm } & & 0.100 & 0.001 & & -0.062 & -0.036 \\
\hline & & $(0.156)$ & $(0.163)$ & & $(0.218)$ & $(0.240)$ \\
\hline \multirow[t]{2}{*}{ farmf } & & 0.056 & 0.074 & & -0.012 & -0.002 \\
\hline & & $(0.085)$ & $(0.087)$ & & $(0.113)$ & $(0.113)$ \\
\hline \multirow[t]{2}{*}{ collf } & & -0.007 & 0.002 & & -0.101 & -0.107 \\
\hline & & $(0.071)$ & $(0.072)$ & & (0.099) & $(0.098)$ \\
\hline \multirow[t]{2}{*}{ privf } & & 0.024 & 0.041 & & $-0.176^{*}$ & -0.168 \\
\hline & & $(0.081)$ & $(0.083)$ & & (0.105) & $(0.104)$ \\
\hline
\end{tabular}




\begin{tabular}{|c|c|c|c|c|c|c|}
\hline \multirow[t]{2}{*}{ govef } & & 0.101 & $0.128 *$ & & & -0.055 \\
\hline & & $(0.073)$ & $(0.075)$ & & $(0.100)$ & $(0.100)$ \\
\hline \multirow[t]{2}{*}{ foref } & & -0.051 & -0.130 & & -0.031 & -0.171 \\
\hline & & $(0.241)$ & $(0.238)$ & & $(0.417)$ & $(0.426)$ \\
\hline \multirow[t]{2}{*}{ farm } & & $-0.221 * * *$ & $-0.234 * * *$ & & $-0.196 * *$ & $-0.200 * *$ \\
\hline & & $(0.066)$ & $(0.067)$ & & $(0.088)$ & $(0.091)$ \\
\hline \multirow[t]{2}{*}{ collm } & & $-0.115^{* *}$ & $-0.109 * *$ & & -0.015 & -0.023 \\
\hline & & $(0.051)$ & $(0.053)$ & & $(0.064)$ & $(0.066)$ \\
\hline \multirow[t]{2}{*}{ privm } & & 0.031 & 0.020 & & 0.055 & 0.032 \\
\hline & & $(0.069)$ & $(0.072)$ & & $(0.092)$ & $(0.094)$ \\
\hline \multirow[t]{2}{*}{ govem } & & $0.133^{* *}$ & $0.142 * *$ & & $0.174 * *$ & $0.179 * *$ \\
\hline & & $(0.062)$ & $(0.064)$ & & $(0.072)$ & $(0.074)$ \\
\hline \multirow[t]{2}{*}{ forem } & & $0.486 * *$ & $0.367^{*}$ & & -0.021 & -0.190 \\
\hline & & $(0.205)$ & $(0.200)$ & & $(0.295)$ & $(0.247)$ \\
\hline \multirow[t]{2}{*}{ Inincome } & & $0.062 * * *$ & $0.069 * * *$ & & 0.025 & $0.038^{*}$ \\
\hline & & $(0.016)$ & $(0.017)$ & & $(0.020)$ & $(0.020)$ \\
\hline \multirow[t]{2}{*}{ tap } & & & $-0.059 *$ & & & -0.043 \\
\hline & & & $(0.032)$ & & & $(0.040)$ \\
\hline \multirow[t]{2}{*}{ flush } & & & 0.023 & & & -0.028 \\
\hline & & & $(0.042)$ & & & $(0.055)$ \\
\hline \multirow[t]{2}{*}{ smokep } & & & 0.270 & & & 0.175 \\
\hline & & & $(0.172)$ & & & $(0.220)$ \\
\hline \multirow[t]{2}{*}{ hfdis } & & & -0.021 & & & -0.013 \\
\hline & & & $(0.013)$ & & & $(0.014)$ \\
\hline Year dummies & yes & yes & yes & yes & yes & yes \\
\hline Obs & 9,776 & 9,610 & 9,191 & 4,878 & 4,788 & 4,580 \\
\hline
\end{tabular}

Notes: (1) regressions are based on the rural data; sample size for wzscore regressions are smaller mainly because WHO only provides formulae for weight-for-age $\mathrm{z}$ scores for children age 10 or under. $(2)^{* * *}, * *$ and $*$ denote statistical significance at $1 \%, 5 \%$ and $10 \%$ level, respectively; clustered standard errors (at household level) are reported in parentheses. (3) MHealth and FHealth denote mother's health (heightm, weightm) and father's health (heightf, weightf) indicators, which correspond to the child health indicators (hzscore, wzscore). 
Table 3 Random Effects Regression Results

\begin{tabular}{|c|c|c|c|c|}
\hline \multirow{3}{*}{ Variable } & \multicolumn{2}{|c|}{ Urban Sample } & \multicolumn{2}{|c|}{ Rural Sample } \\
\hline & hzscore & wzscore & hzscore & wzscore \\
\hline & (1) & (2) & (3) & (4) \\
\hline \multirow[t]{2}{*}{ MHealth } & $0.044 * * *$ & $0.026 * * *$ & $0.044^{* * *}$ & $0.022 * * *$ \\
\hline & $(0.004)$ & $(0.004)$ & $(0.003)$ & $(0.002)$ \\
\hline \multirow[t]{2}{*}{ FHealth } & $0.036^{* * *}$ & $0.023 * * *$ & $0.034 * * *$ & $0.030 * * *$ \\
\hline & $(0.005)$ & $(0.004)$ & $(0.004)$ & $(0.003)$ \\
\hline \multirow[t]{2}{*}{ age } & $0.040^{*}$ & $-0.234 * * *$ & $0.026 * *$ & $-0.232 * * *$ \\
\hline & $(0.021)$ & $(0.043)$ & $(0.012)$ & $(0.025)$ \\
\hline \multirow[t]{2}{*}{ age $^{2}$} & $-0.002^{* *}$ & $0.015^{* * *}$ & $-0.001^{* *}$ & $0.013^{* * *}$ \\
\hline & $(0.001)$ & $(0.004)$ & $(0.001)$ & $(0.002)$ \\
\hline \multirow[t]{2}{*}{ female } & -0.051 & -0.040 & -0.011 & $-0.121 * * *$ \\
\hline & $(0.046)$ & $(0.056)$ & $(0.027)$ & $(0.033)$ \\
\hline \multirow[t]{2}{*}{ agef } & $0.015^{* *}$ & $0.025^{* *}$ & 0.005 & -0.008 \\
\hline & $(0.007)$ & $(0.010)$ & $(0.005)$ & $(0.005)$ \\
\hline \multirow[t]{2}{*}{ agem } & -0.001 & $-0.025^{* *}$ & 0.006 & $0.011^{*}$ \\
\hline & $(0.008)$ & $(0.011)$ & $(0.006)$ & $(0.006)$ \\
\hline \multirow[t]{2}{*}{ east } & $0.368 * * *$ & $0.551^{* * *}$ & $0.381^{* * *}$ & $0.535^{* * *}$ \\
\hline & $(0.075)$ & $(0.090)$ & $(0.046)$ & $(0.054)$ \\
\hline \multirow[t]{2}{*}{ central } & $0.222 * * *$ & $0.284 * * *$ & $0.209 * * *$ & $0.302 * * *$ \\
\hline & $(0.061)$ & $(0.078)$ & $(0.041)$ & $(0.049)$ \\
\hline \multirow[t]{2}{*}{ prif } & -0.060 & -0.095 & 0.104 & -0.086 \\
\hline & $(0.174)$ & $(0.266)$ & $(0.093)$ & $(0.121)$ \\
\hline \multirow[t]{2}{*}{ juf } & 0.101 & 0.089 & 0.087 & -0.159 \\
\hline & $(0.180)$ & $(0.265)$ & (0.094) & $(0.123)$ \\
\hline \multirow[t]{2}{*}{ senf } & 0.044 & -0.086 & 0.098 & -0.054 \\
\hline & $(0.185)$ & $(0.265)$ & $(0.098)$ & $(0.127)$ \\
\hline \multirow[t]{2}{*}{ colf } & 0.235 & 0.010 & 0.188 & -0.000 \\
\hline & $(0.200)$ & $(0.288)$ & $(0.147)$ & $(0.215)$ \\
\hline \multirow[t]{2}{*}{ prim } & $-0.166^{*}$ & -0.034 & $0.100 * *$ & $-0.150 * *$ \\
\hline & $(0.090)$ & (0.148) & $(0.044)$ & $(0.065)$ \\
\hline \multirow[t]{2}{*}{ jum } & -0.109 & 0.126 & $0.168 * * *$ & -0.050 \\
\hline & $(0.098)$ & $(0.152)$ & $(0.049)$ & $(0.066)$ \\
\hline \multirow[t]{2}{*}{ senm } & -0.068 & 0.174 & $0.208^{* * *}$ & -0.061 \\
\hline & $(0.111)$ & $(0.160)$ & $(0.066)$ & $(0.081)$ \\
\hline \multirow[t]{2}{*}{ colm } & -0.110 & $0.502 * *$ & 0.100 & -0.015 \\
\hline & $(0.150)$ & (0.199) & $(0.171)$ & $(0.243)$ \\
\hline \multirow[t]{2}{*}{ farmf } & -0.100 & -0.076 & 0.058 & -0.036 \\
\hline & (0.119) & $(0.183)$ & $(0.080)$ & (0.108) \\
\hline \multirow[t]{2}{*}{ collf } & 0.019 & -0.060 & -0.004 & -0.125 \\
\hline & $(0.080)$ & $(0.120)$ & $(0.068)$ & (0.095) \\
\hline \multirow[t]{2}{*}{ privf } & 0.011 & -0.017 & 0.041 & $-0.184^{*}$ \\
\hline & $(0.088)$ & $(0.132)$ & $(0.080)$ & (0.101) \\
\hline
\end{tabular}




\begin{tabular}{ccccc} 
govef & 0.034 & 0.019 & 0.076 & -0.101 \\
& $(0.080)$ & $(0.112)$ & $(0.069)$ & $(0.096)$ \\
foref & 0.187 & 0.151 & -0.141 & -0.265 \\
& $(0.287)$ & $(0.318)$ & $(0.230)$ & $(0.490)$ \\
farmm & $0.250^{* *}$ & 0.009 & $-0.185^{* * *}$ & $-0.173^{*}$ \\
& $(0.111)$ & $(0.177)$ & $(0.058)$ & $(0.089)$ \\
collm & -0.017 & $-0.195^{* *}$ & $-0.110^{* *}$ & -0.019 \\
& $(0.065)$ & $(0.098)$ & $(0.047)$ & $(0.064)$ \\
privm & $0.169^{*}$ & 0.093 & -0.010 & 0.032 \\
& $(0.090)$ & $(0.140)$ & $(0.069)$ & $(0.088)$ \\
govem & 0.060 & -0.061 & $0.105^{*}$ & $0.212^{* * *}$ \\
& $(0.065)$ & $(0.091)$ & $(0.058)$ & $(0.071)$ \\
forem & -0.019 & $-0.589^{* *}$ & 0.219 & -0.174 \\
& $(0.162)$ & $(0.256)$ & $(0.182)$ & $(0.261)$ \\
Inincome & 0.037 & 0.035 & $0.045^{* * *}$ & 0.022 \\
& $(0.023)$ & $(0.031)$ & $(0.014)$ & $(0.020)$ \\
tap & 0.030 & -0.035 & -0.020 & -0.021 \\
& $(0.057)$ & $(0.082)$ & $(0.027)$ & $(0.036)$ \\
flush & $0.080^{*}$ & 0.020 & 0.009 & -0.036 \\
& $(0.047)$ & $(0.062)$ & $(0.036)$ & $(0.052)$ \\
smokep & 0.171 & -0.568 & 0.232 & 0.121 \\
& $(0.273)$ & $(0.353)$ & $(0.157)$ & $(0.211)$ \\
hfdis & -0.003 & $0.050^{*}$ & -0.016 & $-0.028^{* *}$ \\
& $(0.018)$ & $(0.027)$ & $(0.012)$ & $(0.014)$ \\
\hline Obs & 3,558 & 1,716 & 9,191 & 4,580 \\
\hline
\end{tabular}

Notes: (1) All regressions are based on random effects models controlling for household heterogeneity. (2) $* * *, * *$ and $*$ denote statistical significance at $1 \%, 5 \%$ and $10 \%$ level respectively; clustered standard errors (at household level) are reported in parentheses. (3) MHealth and FHealth denote mother's health (heightm, weightm) and father's health (heightf, weightf) indicators, which correspond to the child health indicators (hzscore, wzscore). 
Table 4 Blinder-Oaxaca Decomposition of Urban-rural Inequality in Child Health

\begin{tabular}{|c|c|c|c|c|c|}
\hline \multirow{2}{*}{\multicolumn{2}{|c|}{ Inequality decomposition }} & \multicolumn{2}{|c|}{ hzscore } & \multicolumn{2}{|c|}{ wzscore } \\
\hline & & \multirow{2}{*}{$\begin{array}{c}\text { Estimated } \\
\text { effects } \\
(1)\end{array}$} & \multirow{2}{*}{$\begin{array}{c}\begin{array}{c}\text { Robust } \\
\text { std.error }\end{array} \\
(2) \\
\end{array}$} & \multirow{2}{*}{$\begin{array}{c}\begin{array}{c}\text { Estimated } \\
\text { effects }\end{array} \\
(3)\end{array}$} & \multirow{2}{*}{$\begin{array}{c}\begin{array}{c}\text { Robust } \\
\text { std.error }\end{array} \\
(4) \\
\end{array}$} \\
\hline & & & & & \\
\hline Overall & -rural disparity & $0.345^{* * *}$ & (0.039) & $0.236 * * *$ & $(0.047)$ \\
\hline Total & wment effect & $0.202 * * *$ & $(0.032)$ & $0.114^{* * *}$ & $(0.037)$ \\
\hline Total c & ination effect & $0.144 * * *$ & $(0.031)$ & $0.122 * * *$ & $(0.038)$ \\
\hline \multirow{9}{*}{$\begin{array}{l}\text { Detailed } \\
\text { endowment } \\
\text { effects }\end{array}$} & Parent health & $0.051 * * *$ & (0.019) & $0.064 * * *$ & $(0.018)$ \\
\hline & Parent income & $0.030 * * *$ & $(0.007)$ & $0.019 * *$ & $(0.008)$ \\
\hline & Parent education & $0.031 * * *$ & $(0.010)$ & $0.027^{* *}$ & $(0.012)$ \\
\hline & Parent employment & $0.091 * * *$ & $(0.012)$ & $0.063^{* * *}$ & $(0.014)$ \\
\hline & Environment & -0.002 & $(0.013)$ & -0.017 & $(0.017)$ \\
\hline & Access to care & 0.000 & $(0.000)$ & 0.000 & $(0.001)$ \\
\hline & Demographic & 0.004 & $(0.004)$ & $-0.015^{*}$ & $(0.008)$ \\
\hline & Year fixed effect & $0.011^{* *}$ & $(0.005)$ & 0.005 & $(0.006)$ \\
\hline & Region fixed effect & $-0.015^{* * *}$ & $(0.005)$ & $-0.030 * * *$ & $(0.011)$ \\
\hline \multirow{9}{*}{$\begin{array}{c}\text { Detailed } \\
\text { discrimination } \\
\text { effects }\end{array}$} & Parent health & 0.739 & $(1.022)$ & -0.115 & (0.309) \\
\hline & Parent income & -0.201 & $(0.252)$ & 0.124 & $(0.306)$ \\
\hline & Parent education & -0.286 & $(0.212)$ & 0.318 & $(0.225)$ \\
\hline & Parent employment & -0.036 & $(0.094)$ & -0.148 & $(0.133)$ \\
\hline & Environment & 0.051 & (0.133) & -0.192 & $(0.168)$ \\
\hline & Access to care & 0.010 & $(0.010)$ & 0.019 & $(0.014)$ \\
\hline & Demographic & 0.137 & $(0.217)$ & 0.135 & $(0.270)$ \\
\hline & Year fixed effect & -0.007 & $(0.045)$ & -0.034 & $(0.054)$ \\
\hline & Region fixed effect & 0.020 & $(0.047)$ & -0.020 & $(0.057)$ \\
\hline
\end{tabular}

Notes: (1) statistics reported are the estimated effects based on the two-fold Blinder-Oaxaca decomposition and the robust standard errors (in parentheses) computed using the delta method; (2) $* * *, * *$ and $*$ denote statistical significance at $1 \%, 5 \%$ and $10 \%$ level, respectively;. (3) Detailed endowment / discrimination effects are grouped into the following dimensions: parent health (MHealthit and FHealthit), parent income (Inincome), parent education (prif, juf, senf, colf, prim, jum, senm, colm), parent employment (farmf, collf, privf, govef, foref, othef, farm, collm, privm, govem, forem, othem), household environment (tap water, flush toilet, community smoking prevalence), access to care (distance to nearest health facility), demographic factors (female, age, age ${ }^{2}$, agef, agem), year fixed effect (y93, y97, y00, y04, y06, y09)and region fixed effect (east, central). 
Table 5 Nature-Nurture Interaction in Intergenerational Health Transmission

\begin{tabular}{|c|c|c|c|c|c|c|c|c|c|}
\hline \multirow[t]{2}{*}{ Variable } & income & gfworkf & gfworkm & eyf & eym & tap & flush & smokep & hfdis \\
\hline & (1) & (2) & (3) & (4) & (5) & (8) & (9) & (10) & (11) \\
\hline \multicolumn{10}{|c|}{ Urban Sample } \\
\hline \multirow[t]{2}{*}{ heightf } & $0.009 * * *$ & $0.012 * * *$ & $0.011^{* * *}$ & $0.070 * * *$ & $0.101^{* * *}$ & $0.003^{*}$ & $0.007^{* * *}$ & $-0.001 * * *$ & 0.003 \\
\hline & $(0.003)$ & $(0.002)$ & $(0.002)$ & $(0.014)$ & $(0.014)$ & $(0.002)$ & $(0.002)$ & $(0.000)$ & $(0.003)$ \\
\hline \multirow[t]{2}{*}{ heightm } & $0.013 * * *$ & $0.005^{* *}$ & $0.004 *$ & $0.095 * * *$ & $0.074 * * *$ & $0.004 * *$ & $0.007 * * *$ & 0.000 & -0.002 \\
\hline & $(0.004)$ & $(0.002)$ & $(0.002)$ & $(0.016)$ & $(0.016)$ & $(0.002)$ & $(0.002)$ & $(0.000)$ & $(0.004)$ \\
\hline Obs & 3,977 & 3,994 & 3,997 & 3,849 & 3,813 & 4,031 & 4,031 & 4,031 & 3,830 \\
\hline \multirow[t]{2}{*}{ weightf } & $0.011^{* * *}$ & $0.005^{* * *}$ & $0.004^{* * *}$ & $0.032 * * *$ & $0.037^{* * *}$ & $0.003^{* * *}$ & $0.005^{* * *}$ & $-0.000 * *$ & 0.000 \\
\hline & $(0.002)$ & $(0.001)$ & $(0.001)$ & $(0.006)$ & $(0.006)$ & $(0.001)$ & $(0.001)$ & $(0.000)$ & $(0.002)$ \\
\hline \multirow[t]{2}{*}{ weightm } & 0.002 & 0.001 & 0.000 & -0.003 & -0.001 & 0.001 & -0.000 & $0.000 * *$ & -0.003 \\
\hline & $(0.003)$ & $(0.001)$ & $(0.001)$ & $(0.007)$ & $(0.007)$ & $(0.001)$ & $(0.001)$ & $(0.000)$ & $(0.002)$ \\
\hline Obs & 3,921 & 3,940 & 3,943 & 3,792 & 3,754 & 3,975 & 3,975 & 3,975 & 3,777 \\
\hline \multicolumn{10}{|c|}{ Rural Sample } \\
\hline \multirow[t]{2}{*}{ heightf } & $0.012 * * *$ & $0.006 * * *$ & $0.005 * * *$ & $0.054 * * *$ & $0.092 * * *$ & $0.006 * * *$ & $0.005 * * *$ & -0.000 & 0.002 \\
\hline & $(0.002)$ & $(0.001)$ & $(0.001)$ & $(0.010)$ & $(0.012)$ & $(0.002)$ & $(0.001)$ & $(0.000)$ & $(0.003)$ \\
\hline \multirow[t]{2}{*}{ heightm } & 0.004 & $0.006 * * *$ & $0.004^{* * *}$ & $0.028 * * *$ & $0.026 * *$ & $0.005^{* * *}$ & $0.003^{* *}$ & -0.000 & 0.000 \\
\hline & $(0.004)$ & $(0.002)$ & $(0.002)$ & $(0.016)$ & $(0.016)$ & $(0.002)$ & $(0.002)$ & $(0.000)$ & $(0.004)$ \\
\hline Obs & 10,381 & 10,385 & 10,409 & 10,240 & 10,127 & 10,573 & 10,573 & 10,573 & 10,099 \\
\hline \multirow[t]{2}{*}{ weightf } & $0.009 * * *$ & $0.005^{* * *}$ & $0.004 * * *$ & $0.019 * * *$ & $0.024 * * *$ & $0.003 * * *$ & $0.005^{* * *}$ & $-0.000 * *$ & -0.000 \\
\hline & $(0.001)$ & $(0.001)$ & $(0.001)$ & $(0.004)$ & $(0.005)$ & $(0.001)$ & $(0.001)$ & $(0.000)$ & $(0.001)$ \\
\hline \multirow[t]{2}{*}{ weightm } & 0.000 & $0.001 *$ & 0.001 & 0.003 & 0.002 & $0.002 * *$ & 0.001 & 0.000 & 0.002 \\
\hline & $(0.002)$ & $(0.001)$ & $(0.001)$ & (0.004) & $(0.005)$ & $(0.001)$ & (0.001) & $(0.000)$ & $(0.002)$ \\
\hline Obs & 10,271 & 10,278 & 10,301 & 10,131 & 10,017 & 10,463 & 10,463 & 10,463 & 9,990 \\
\hline
\end{tabular}

Notes: (1) All regressions are based on random effects models controlling for household heterogeneity. (2) All models contain individual level control variables such as age, age ${ }^{2}$, female, agef, agem, region dummies and year dummies. (3) gfworkf and gfworkm are dummy variables, indicating if father or mother works in government, SOE or foreign enterprise; eyf and eym are the formal schooling years of father and mother, respectively. (4) $* * *, * *$ and * denote statistical significance at $1 \%, 5 \%$ and $10 \%$ level, respectively; clustered standard errors (at household level) are reported in parentheses. 


\section{Economics Working Papers}

2013-08: Christian Bjørnskov: Types of Foreign Aid

2013-09: John Kennes and Daniel le Maire: Job Heterogeneity and Coordination Frictions

2013-10: Peter Arendorf Bache and Anders Laugesen: Monotone Comparative Statics for the Industry Composition under Monopolistic Competition

2013-11: $\quad$ Anders Frederiksen and Jesper Rosenberg Hansen: Trends in Sector Switching: Evidence from Employer-Employee Data

2013-12: $\quad$ Mongoljin Batsaikhan and Norovsambuu Tumennasan: Price-Matching leads to the Cournot Outcome

2013-13: Sylvanus Kwaku Afesorgbor: Revisiting the Effectiveness of African Economic Integration. A Meta-Analytic Review and Comparative Estimation Methods

2013-14: Peter Arendorf Bache and Anders Laugesen: Trade Liberalisation and Vertical Integration

2013-15: Kaleb Girma Abreha, Valérie Smeets and Frédéric Warzynski: Coping with the Crisis: Recent Evolution in Danish Firms' - International Trade Involvement, 2000-2010

2013-16: $\quad$ Peter Arendorf Bache and Anders Laugesen: An Industry-Equilibrium Analysis of the LeChatelier Principle

2013-17: $\quad$ Anna Piil Damm and Christian Dustmann: Does Growing Up in a High Crime Neighborhood Affect Youth Criminal Behavior?

2013-18: Christian Bjørnskov and Jacob Mchangama: Do Social Rights Affect Social Outcomes?

2013-19: Benoit Julien, John Kennes, and Moritz Ritter: Bidding for Clubs

2013-20: Ina Charlotte Jäkel: Import-push or Export-pull?

2013-21: Tor Eriksson, Jay Pan and Xuezheng Qin : The Intergenerational Inequality of Health in China 